\title{
Analyses of six homologous proteins of Protochlamydia amoebophila UWE25 encoded by large GC-rich genes (Igr): a model of evolution and concatenation of leucine-rich repeats
} Myriam Eugster ${ }^{1}$, Claude-Alain H Roten ${ }^{1,2}$ and Gilbert Greub*1

Address: ${ }^{1}$ Center for Research on Intracellular Bacteria (CRIB), Institute of Microbiology, University Hospital Center and University of Lausanne, Switzerland and ${ }^{2}$ Comparative Genometrics Center (CGC), Department of Fundamental Microbiology, University of Lausanne, Lausanne, Switzerland

Email: Myriam Eugster - myriam.eugster@gmail.com; Claude-Alain H Roten - claude.alain.roten.cgc@gmail.com; Gilbert Greub* - gilbert.greub@chuv.ch

* Corresponding author

Published: 16 November 2007

BMC Evolutionary Biology 2007, 7:231 doi:10.1 186/I47|-2|48-7-23।
Received: 3 May 2007

Accepted: 16 November 2007

This article is available from: http://www.biomedcentral.com/|47|-2|48/7/23 |

(C) 2007 Eugster et al; licensee BioMed Central Ltd.

This is an Open Access article distributed under the terms of the Creative Commons Attribution License (http://creativecommons.org/licenses/by/2.0), which permits unrestricted use, distribution, and reproduction in any medium, provided the original work is properly cited.

\begin{abstract}
Background: Along the chromosome of the obligate intracellular bacteria Protochlamydia amoebophila UWE25, we recently described a genomic island Pam 100G. It contains a tra unit likely involved in conjugative DNA transfer and $l g r E$, a $5.6-\mathrm{kb}$ gene similar to five others of $P$. amoebophila: $\operatorname{lgr} A$ to $\operatorname{lgr} \mathrm{D}$, IgrF. We describe here the structure, regulation and evolution of these proteins termed LGRs since encoded by "Large G+C-Rich" genes.
\end{abstract}

Results: No homologs to the whole protein sequence of LGRs were found in other organisms. Phylogenetic analyses suggest that serial duplications producing the six LGRs occurred relatively recently and nucleotide usage analyses show that $\operatorname{lgrB}$, $\operatorname{lgr} E$ and $\lg r F$ were relocated on the chromosome. The C-terminal part of LGRs is homologous to Leucine-Rich Repeats domains (LRRs). Defined by a cumulative alignment score, the 5 to 18 concatenated octacosapeptidic (28-meric) LRRs of LGRs present all a predicted $\alpha$-helix conformation. Their closest homologs are the 28-residue RI-like LRRs of mammalian NODs and the 24-meres of some Ralstonia and Legionella proteins. Interestingly, IgrE, which is present on Pam I00G like the tra operon, exhibits Pfam domains related to DNA metabolism.

Conclusion: Comparison of the LRRs, enable us to propose a parsimonious evolutionary scenario of these domains driven by adjacent concatenations of LRRs. Our model established on bacterial LRRs can be challenged in eucaryotic proteins carrying less conserved LRRs, such as NOD proteins and Toll-like receptors.

\section{Background}

Candidatus Protochlamydia amoebophila UWE25 (hereafter named $P$. amoebophila) is an obligate intracellular symbiont infecting free-living amoebae [1]. Presenting significant gene sequence similarity with sequences of Chlamydia spp, this related bacterium exhibits a Chlamydia-like developmental cycle, which includes i) the proliferating reticulate body observed only within amoebae, ii) the infecting elementary body that may be found in amoebal vacuoles early after internalization, and iii) the crescent body considered as an additional infectious stage [2,3]. P. amoebophila belongs to the Parachlamydiaceae family, 
composed of, at least, two additional genera represented by Parachlamydia acanthamoebae [4] and Neochlamydia hartmannellae [5]. Parachlamydia was recently recognized as a novel agent of pneumonia (reviewed in $[6,7]$ ). Serological and molecular evidences suggested its role as an agent of community-acquired pneumonia [8-10] and aspiration pneumonia [11]. Moreover, we demonstrated that Parachlamydia may survive to human macrophages [12], by remaining somehow unrecognized from these major innate immune cells [13], by modulating the fate of the Parachlamydia-containing vacuole [14], and by inducing macrophage apoptosis [12].

The genome size of $P$. amoebophila is twice larger than the published genome sequences of Chlamydiaceae [15]. Preliminary genome analyses by Horn and coworkers showed the presence of transposases and of a cluster of high $\mathrm{G}+\mathrm{C}$ content genes likely transferred horizontally [15]. The latter genes encode a type IV secretion system, supposed to be involved in the secretion of effector proteins $[15,16]$. However, Horn and coworkers did not identify traA, traL, traK and traV, and misannotated as traF an ORF similar to trsF carried by plasmid R391 of Proteus rettgeri $[15,17]$.

After reannotation, identification of the four supplementary tra genes, and additional phylogenetic analyses based either on concatenated tra genes or on gene order comparison, we proposed that this type IV secretion system can play a role in conjugative DNA transfer and originated in proteobacteria [17]. The presence of similar tra operons on the pRF plasmid of Rickettsia felis [18] and on the circular chromosome of Rickettsia bellii [19], as well as the observation of sexual pili by electron microscopy of these two obligate intracellular bacteria $[18,19]$ further supported that the gene products of the tra operon of $P$. amoebophila UWE25 are involved in conjugative DNA transfer. Furthermore, the concatenated tra genes of both rickettsia and $P$. amoebophila clustered in the maximum likelihood tree with a 95\% bootstrap value [19].

In silico comparative genomics along this genome sequence enabled us to identify for the first time the genomic island Pam100G [17]. This inserted 100-kb mobile element is delimited by the presence of two $g l y$ tRNA genes in tandem at its $5^{\prime}$ end, and by direct repeats located at both ends [17]. Pam100G present a modular composition of its $\mathrm{G}+\mathrm{C}$ content. The first module exhibits a $\mathrm{G}+\mathrm{C}$ content $(36.4 \%)$ similar to that of the host $(36.1 \%)$ and contains a set of genes likely generated by chromosomal rearrangements. Then, three modules, which contain low $\mathrm{G}+\mathrm{C}$ content (33.3-34.1\%) phage-related genes, are intercalated with three high $\mathrm{G}+\mathrm{C}$ content modules (38.7\%-41.8\%) [17]. The first G+C-rich module carried the type IV secretion system partially reported by Horn et al. [15]. The putative mobility of Pam100G as a conjugative plasmid was strongly supported by the identification of an episome carrying a similar tra unit during the genome sequence analyses of strain ATCC VR1471 of Simkania negevensis, a related bacterium (Myers G., oral presentation at the Chlamydia Basic Research Society Meeting, Indianapolis, 2005). The latter tra sequences are already available for BLAST analyses [20]. Interestingly, the genomic island of $P$. amoebophila also carries a huge 5.6$\mathrm{kb}$ gene (pc1455). This gene, now called $\lg r E$, is located 10 $\mathrm{kb}$ after the 3 '-end of the tra unit (see below). It corresponds to the second high $\mathrm{G}+\mathrm{C}$ content module $(41.8 \%)$, suggesting it may, like the tra operon, have emerged in a common genomic environment similar to that of some alpha-, gamma-, delta- or epsilon-proteobacteria. This gene encodes one of the largest protein of $P$. amoebophila (1866 amino acids) exhibiting some similarities with the mammalian NOD3, a protein carrying LRR units [17].

The family of eucaryotic cytoplasmic proteins defined by a Nucleotide-binding Oligomerization Domain (NOD) [21] presents gene products exhibiting various functions ranging from regulators of apoptosis (such as Apaf-1) to proteins implicated in resistance against pathogens in mammals (NOD1, NOD2) and plants ( $\mathrm{R}$ genes, $\mathrm{R}$ for resistance). Both $\mathrm{R}$ genes and mammalian NODs are composed of effector domains such as the CAspase Recruitment Domain (CARD) or the PYrin Domain (PYD, protein module defined by Bertin et al. [22] found in proteins that are thought to function in apoptotic and inflammatory signaling pathways), and of a carboxy-terminal leucine-rich repeat domain (LRRs) used in pathogen recognition. The NODs proteins also exhibit a NOD domain, which induces its self-oligomerization. LRR domains are concatenated repeats of 20- to 29-residue motifs present in all clades from viruses to eucaryotes. They have been classified in seven different subfamilies (reviewed in [23]). One of them, the ribonuclease inhibitor (RI)-like subfamily (RI-like LRR) is present in intracellular proteins of eucaryotes and exhibits the longest LRR motifs: 28-29 residues [23]. The LRRs of NOD proteins are the most studied RI-like LRRs. This ligand recognition domain is involved in the recognition of basic units of peptidoglycan, i.e. a common bacterial component: NOD1 recognizes the widely spread dipeptide $\gamma$-D-glutamyl-mesodiaminopimelate, and NOD2 the universal muramyl-Lalaninyl-D-glutamate, known as muramyl-dipeptide (MDP). The function of the NOD3 protein still remains unknown.

In this report, we described (i) the evolutionary history of the $\lg r E$ gene and of five paralogs $(\lg r A-\lg r D, \lg r F)$ present in the genome of $P$. amoebophila, (ii) the structure of the corresponding gene products and, finally, (iii) the structural and phylogenetic relationships existing between 
their LRR domains. Since almost no tools are available for molecular biology experiments on Chlamydiales, a putative regulation of these $\lg r$ genes and a possible role of these large proteins are proposed, based on various in silico analyses.

\section{Results and discussion}

P. amoebophila proteins homologous to LgrE

Using BLASTP, five additional large proteins homologous to the whole $\lg r E$ gene product were identified in the genome of $P$. amoebophila (Table 1). We named the six ORFs coded by large $\mathrm{G}+\mathrm{C}$ rich genes $\lg \mathrm{A} A$ to $\lg \mathrm{F}$ according to their position on the published chromosome sequence, starting from the putative origin of DNA replication indicated by GC skew analyses. Figures $1 \mathrm{~A}$ and $1 \mathrm{E}$ show that these genes are scattered along the chromosome of the bacterium. As revealed by cumulative GC skew analyses (Figure 1A), lgrE is associated to the local inversion of the signal that highlights Pam100G, an already described genomic island [17].

With more than 4500 nucleotides, the six $\lg r$ genes are among the 15 largest ORFs of the P. amoebophila genome. The presence of these six very similar ORFs, which likely originated by serial duplications from an unique ancestral gene, and not found in other sequenced bacteria, suggests that these proteins probably play an important role in the particular biology of these bacteria.

The genomic $\mathrm{G}+\mathrm{C}$ content analysis displayed on Figure $1 \mathrm{~B}$ shows that, with a $\mathrm{G}+\mathrm{C}$ content ranging from 41.4 to $43.1 \%$, the six lgrs present a G+C content higher than that of the average of the rest of the genome, suggesting a foreign origin. Due to a similar $\mathrm{G}+\mathrm{C}$ content, all lgrs proteins might have a common origin with the tra operon, which most probably originated in proteobacteria [17]. Among the 2031 ORFs of $P$. amoebophila, 156 present a G+C con- tent of more than $40 \%$, including among others 28 ribosomal protein genes and all $\lg r \mathrm{~s}$, the latters being the only high $\mathrm{G}+\mathrm{C}$ ORFs encoding proteins larger than one thousand amino acids. As expected, all lgrs display a positive steep slope in the residual cumulative $\mathrm{G}+\mathrm{C}$ content curve, due to their $\mathrm{G}+\mathrm{C}$ content higher than the chromosome counterpart (Figure 1C). Of note, no particular gene environment of the lgrs could be highlighted by this analysis, except the already described genomic island, Pam100G, associated to $\lg E$ [17].

All lgrs exhibit at the third codon position an enrichment in Cs characteristic of genes anti-oriented to chromosome replication [24], revealing that their common ancestor was most probably unique and anti-oriented. However, $\lg r B, \lg r E$ and $\lg r F$, are currently co-oriented (Figure 1D) and seem to exhibit an adaptation to this new relative position to chromosome replication, since their third codon position is slightly enriched in Gs (Figure 1E). Consequently, we may hypothesize that the currently co-oriented $\lg E$ probably duplicated recently from the antioriented $\lg r A$ gene, and that $\lg r B, \lg E$ and $\lg r F$, changed their orientation about at the same time, suggesting intense gene re-arrangements in a recent period during P. amoebophila speciation. The source of such genes rearrangements could be similar to the intense genetic exchanges revealed in Pam100G by the presence of the tra unit and the phage-related genes, i.e conjugative DNA transfer and/or transduction.

Furthermore, the six $\lg r$ genes show a very similar codon usage, not significantly different from the codon usage of most proteins of $P$. amoebophila. No particular relationships could be found by this particular analysis between lgrs and different kinds of genes: high G+C ORFs such as ribosomal protein genes, large proteins encoding genes or others (see Additional File 1(A)), and genes of the tra unit

Table I: Characteristics of the six LGR proteins

\begin{tabular}{|c|c|c|c|c|c|c|c|c|c|}
\hline Gene name & $\begin{array}{l}\text { Protein } \\
\text { number }\end{array}$ & Position & Strand & $\begin{array}{c}\text { GC content } \\
(\%)\end{array}$ & Length [bp] & Length [aa] & $\begin{array}{l}\text { Length of } \\
\text { LRR region } \\
\text { [aa] }\end{array}$ & $\begin{array}{c}\text { Number of } \\
\text { LRR }\end{array}$ & $\begin{array}{l}\text { Identities } \\
\text { with LgrE } \\
\text { (BLASTP) }\end{array}$ \\
\hline $\lg A$ & pc0264 & $\begin{array}{c}372491- \\
377908\end{array}$ & - & 41.4 & 5418 & 1805 & 446 & 16 & $\begin{array}{c}1590 / 1805 \\
(88 \%)\end{array}$ \\
\hline $\lg B$ & pc0970 & $\begin{array}{c}\text { II64574- } \\
\text { II6939| }\end{array}$ & - & 42.6 & 4818 & 1605 & 239 & 8 & $\begin{array}{c}1153 / 1600 \\
(72 \%)\end{array}$ \\
\hline $\lg r C$ & pcl065 & $\begin{array}{c}1267648- \\
1272165\end{array}$ & + & 41.8 & 4518 & 1505 & 150 & 5 & $\begin{array}{c}1104 / 1505 \\
(73 \%)\end{array}$ \\
\hline $\operatorname{lgr} D$ & pcl34I & $\begin{array}{c}1596253- \\
1601547\end{array}$ & + & 43.1 & 5295 & 1764 & 411 & 15 & $\begin{array}{c}1257 / 1776 \\
(71 \%)\end{array}$ \\
\hline $\lg E$ & pcl455 & $\begin{array}{c}1726283- \\
1731883\end{array}$ & - & 41.8 & 5601 & 1866 & 505 & 18 & $\begin{array}{c}1866 / 1866 \\
(100 \%)\end{array}$ \\
\hline $\operatorname{lgr} F$ & pcl6II & $\begin{array}{c}1924358- \\
1929142\end{array}$ & - & 40.9 & 4785 & 1594 & 225 & 8 & $\begin{array}{c}1194 / 1597 \\
(75 \%)\end{array}$ \\
\hline
\end{tabular}

aa $=$ amino acids

bp = base pairs 


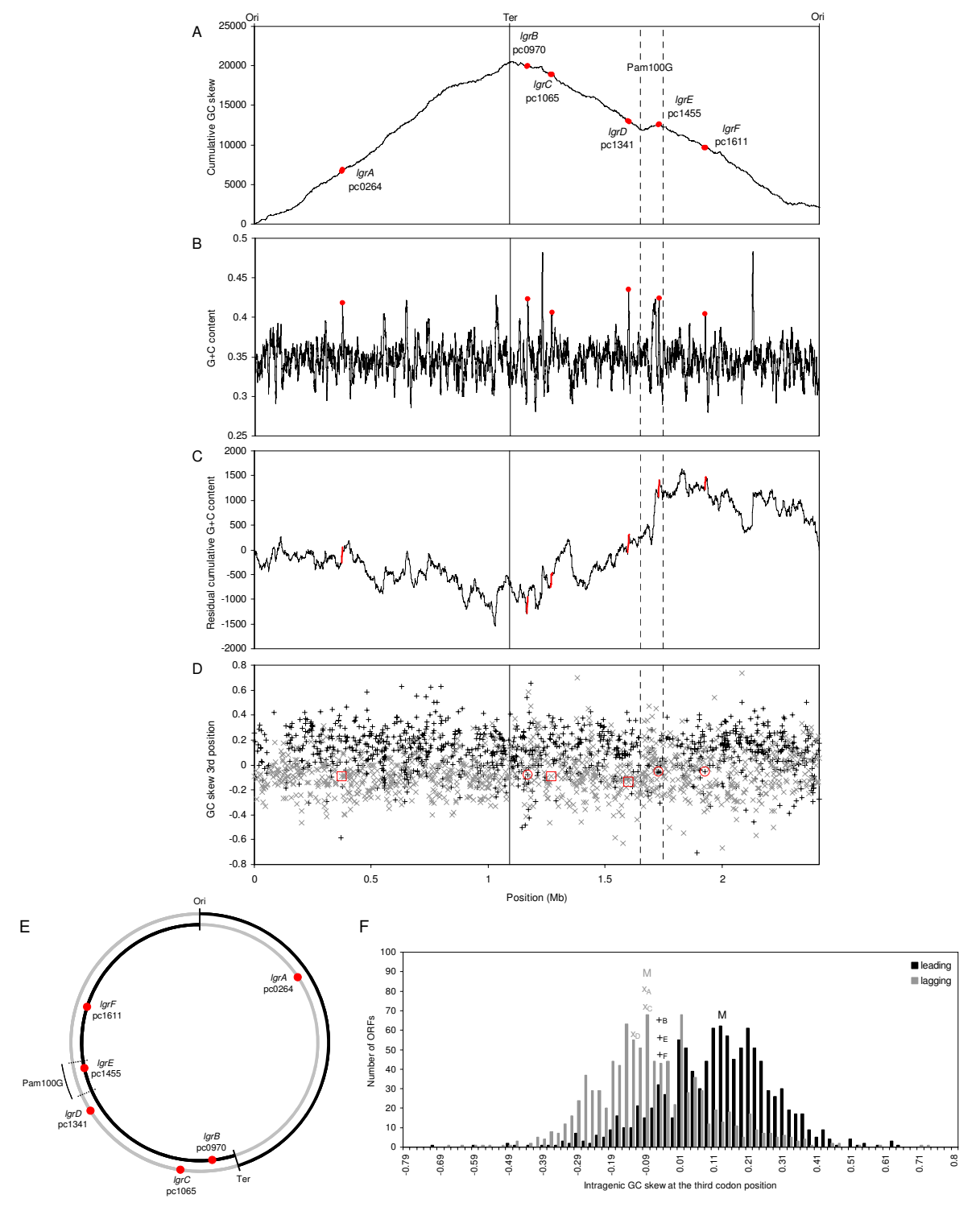

Figure I

A: Position of the six Igr genes of $P$. amoebophila on the cumulative GC skew. B: on the G+C content curve (non-overlapping I-kb windows). C: on the residual cumulative $\mathrm{G}+\mathrm{C}$ content curve (5-kb windows sliding by I-kb step). D: Values of the intragenic GC skew at the third position of the codons $\left(\mathrm{GC}_{3}\right)$ versus the location of all 203 I ORFs of $P$. amoebophila encoded either by the leading $($ black + ) or by the lagging strand (grey $\mathrm{x}$ ), both strands defined by the origin and terminus of replication determined by the minimum and the maximum of the cumulative GC skew curve from Figure IA; open red circles/squares highlight the lgrs located on the leading/lagging strand. E: Chromosome map of $P$. amoebophila showing by red circles the six lgrs encoded on the leading- (black), or the lagging strand (grey). F: Histogram of the $\mathrm{GC}_{3}$ values of all 203I ORFs of $P$. amoebophila located on the leading (1065 ORFs) or lagging strand (988 ORFs). The values of the lgrs encoded by the leading/lagging strand are indicated by black + /grey $x$, and the median $M$ of the leading/lagging strand values is labelled in black/grey. Since all six lgrs present higher $\mathrm{G}+\mathrm{C}$ content than the rest of the genome (34.7\%), they all exhibit steep slopes in the residual cumulative $\mathrm{G}+\mathrm{C}$ content curve. The lgrE is located in Pam I00G, a 100-kb genomic island presenting a particular GC skew profile whose boundaries are indicated by dashed lines in panels $A$ to $E$. The $\mathrm{GC}_{3}$ values of all six lgrs is similar to that of the anti-orientated genes of $P$. amoebophila, although three lgrs are encoded by the leading strand (IgrB, IgrE and lgrF). Since $\mathrm{GC}_{3}$ values of the three latters $(-0.08057$ for $\lg r B,-0.05634$ for $\operatorname{lgr} E$, and -0.05228 for $\operatorname{lgrF})$ are significantly lower than the median minus the standard deviation $(0.129 \pm 0.167)$ of all genes encoded on the leading strand $(p=0.005)$ and close to the median of the genes encoded by the lagging strand (median=-0.09I $\pm 0.17 \mathrm{I}$ ), it appears that an adaptation of the codon usage of these three lgrs is at work, due to a relatively recent re-orientation on the chromosome. 
or the other genes of the genomic island (see Additional File 1(B)). Additional File 1(C) and its magnification (Additional File 1(D)) show that the variation of the codon usage is mainly due to the LRR domain (see below for precise delimitation). It also reveals that $\lg r A$ and $\lg r E$ present a very close codon usage suggesting that both genes result from a duplication more recent than the other $\lg r$ duplications. This hypothesis is confirmed by phylogenetic analyses performed on amino acids and nucleotides sequences with various phylogenetic methods (NeighborJoining [Figure 2A], Minimum Evolution and Maximum Parsimony [data not shown], Maximum Likelihood validated by Bayesian analyses [Figure 2B]).

\section{Overall structure of LGRs}

The alignment of the six LGRs showed that their 1350 first amino acids are very similar (see Additional File 2). The more variable C-terminal part of these proteins presents gaps in the amino acid alignment, most of the latter measuring multiples of 28 residues, thus revealing an octacosapeptidic structure of this protein domain. This less conserved part of these proteins is characterized by the presence of concatenated Leucine-Rich Repeats (LRRs). The variation in the LRR number estimated after a precise delimitation of each unit (see below) almost fully explain the variable length of the six LGRs: the LRR domain varied from 168 to 515 amino acids while the remaining part of the proteins, designated by us as the non-LRR domain, present a very conserved length ranging from 1353 to 1369 amino acids (1360.5 \pm 6.2$)$.

Analyses of the secondary structure of these proteins with NNPREDICT (see Additional File 3(A)) showed a succession of $\alpha$-helices (45.2-46.9\%) and $\beta$-sheets (5.2-7.2\%) in the LRR domain (see Additional File 4) precisely delimited by the cumulative alignment score (see below). In the non-LRR region (ca. 1350 first amino-acids), the proportion of $\alpha$-helices and $\beta$-sheets are quite similar (42.0$46.6 \%$ and $5.8-7.7 \%$, respectively). With the exception of LgrA and LgrE, the percentage of amino acids involved in $\alpha$-helices in the carboxy-terminal region of LGR proteins defined as the LRR domain, is higher than in the rest of the protein (see Additional File 4). The recent duplication of LgrA and LgrE suggested by similarity in codon usage and by phylogenetic analyses (see above) is further supported by the very close secondary structure of these two proteins (Additional File 3(B)). Analyses performed by TMHMM v. 2.0 on the six LGR proteins identified no transmembrane domain. However, when looking for conserved Pfam motifs (see below the paragraph on the putative role of LGRs), we found a conserved domain present in mycoplasmal lipoproteins in LgrA, LgrB, LgrE and LgrF,
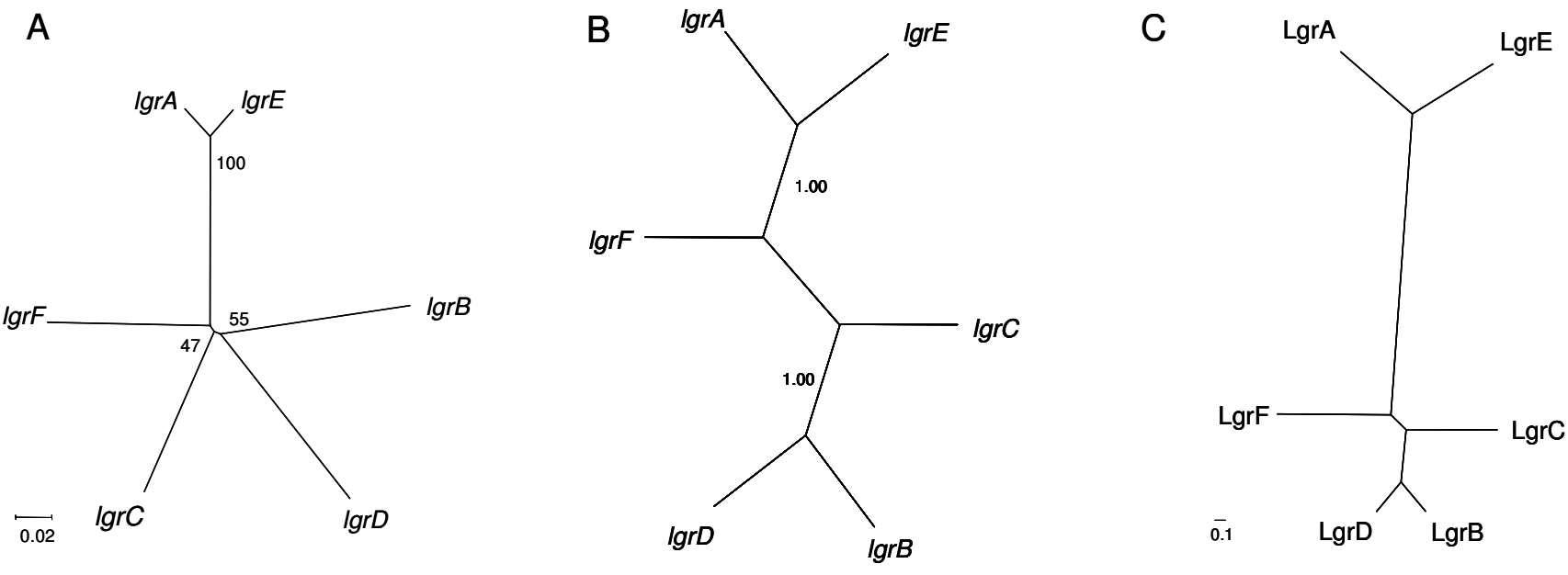

Figure 2

Phylogeny of the six LGR proteins encoding genes (Igr) of $P$. amoebophila. A: Neighbor-Joining tree of the nucleotide sequences of the lgrs without the sequence corresponding to the LRR domain, using the Kimura 2-parameter distance and the complete deletion parameter with a bootstrap analysis of I'000 samples. Bootstrap values are shown in percent. B: Bayesian tree performed on the same non-LRR sequences was drawn after 100'000 generations, sampling 100 generations and 5 chains, respectively. The general-time reversible model was used with gamma rates of among-site variation. C: UPGMA tree based on the comparison of the amino acids composition of the LRRs: same data as those used for Figure 6 to calculate the center of gravity. In all three analyses, IgrA and lgrE are very close. Except in A, in which all other lgrs seem to emerge from the same nod, the relationships between the four others is strikingly conserved in the dendrograms $B$ and $C$. 
suggesting that these LGRs exhibit a prokaryotic membrane attachment site probably acting as a membrane anchor [25].

Finally, we also analyzed the distribution of leucine within all six LGRs (see Additional File 5). While the leucine content of LGRs is higher (13.3 to $14.1 \%$ ) than that of the other proteins encoded by $P$. amoebophila chromosome $(11.7 \%)$, the leucine content of LGRs is not significantly different within the LRR- and non-LRR domains (13.2 to $17.3 \%$ and 13.1 to $13.5 \%$ ). As expected, repetitions of the leucine pattern occur in the LRR domain at a periodic 28-residue interval.

\section{Other proteins of P. amoebophila exhibiting LRR domains: 23-, 25-, and 28-meres}

LRR domains are defined as concatenated leucine-rich repeats units of 20-29 residues that generally fold into an arc or horseshoe shape [23]. BLASTP searches in the genome of $P$. amoebophila of proteins homologous to the LGRs highlights the presence of other LRRs proteins: (i) pc1145, a putative small protein exhibiting two repeats of 28 amino acids similar to the LRRs of the LGRs proteins, (ii) pc0038 containing 23-meric LRRs, and (iii) four additional proteins (pc1032, pc1462, pc1616 and pc0992) presenting 25-residue repeats. Further analyses based on the four latters detected 66 other proteins exhibiting relatively significant similarity to the four 25-meres. Our results describing 78 LRR-carrying proteins encoded on the chromosome of $P$. amoebophila UWE25 and the length of their LRRs extend the recently published preliminary analyses performed independently that identified 56 LRRs proteins in the genome of this strain [16].

\section{Common frame of the 28-meric LRRs determined by the Cumulative Alignment Score}

Similarity analyses performed by BLAST allow rapid determination of LRR polypeptides in LGRs. Unfortunately, a common 28-meric frame shared by the six LGRs could not be proposed by this technique. Although the LRRs are abundantly discussed in the literature, there is no consensus on where each repeat precisely begins and ends. Therefore, we developed the Cumulative Alignment Score (CAS), a non a priori approach designed to unambigously define (i) the start of the LRR domain and (ii) the precise limits of the common unit frame of all LGRs and of other LRR-containing proteins of bacteria, animals and plants.

The representation of the protein sequences of the LGRs versus the CAS scores determined by preliminary common LRR sequences enabled us to precisely define the LRR domain of the six LGR proteins (see Additional File 6). Although the CAS of the six LGRs does not determine an entire number of repeats in the LRR domains, four of the six proteins present a LRR domain varying in length in
LRR units by no more than three residues: LgrA, LgrD, LgrE and LgrF (Table 1, Figure 3). However, the final repeat $L_{R R} R_{15}$ LgrD has a degenerated end and thus exhibits a lower similarity with the others. Therefore, the latter unit was not taken into account by the identity analysis of the CAS (Figure 3). All further analyses on the LRRs are based on repeats defined by the CAS by at least two thirds of the consensual residues.

The LRR domain of the LGR proteins are thus composed of 5 to 18 well conserved units of 28 amino acids composing 70 different LRRs (Figure 3, see Additional File 2). Furthermore, pc1145 also presents two 28-residue LRRs. Interestingly, only one out of these 72 LRRs differs in

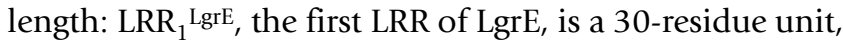
due to a tandem duplication of two codons (GAA-GTTGAA-GTT) encoding the dipeptide Glu-Val present in the first LRR of all other LGRs, except LgrD. We confirmed the existence of this small duplication in $\mathrm{LRR}_{1}{ }^{\mathrm{LgrE}}$ by resequencing this region, as previously described [26], but using the following primers: 5'CGGCTCCCTATATCAAAGGA and 5'GTTACCACCAAGGTAGAGTG.

The determination of the limits of the repeats of the LGRs performed by the CAS is unambiguously confirmed by the determination of a common frame for the six LGRs and by the presence of a conserved secondary structure within each repeat and no standard secondary structure at the LRR boundaries (Figure 4, see Additional Files 3 and $7)$. In several LRRs, amino acids present at the C-terminal part of the repeat were also predicted to be involved in a small $\beta$-sheet made of $\mathrm{Leu}_{19}$, Leu 22 , and $\mathrm{Leu}_{24}$. No other putative $\beta$-sheet was found elsewhere. Glycyl residues that could be part of a turn of the peptide backbone due to their non-stereospecific nature brought by the presence of the hydrogen atom as lateral chain, are always the $5^{\text {th }}$ amino acid of the repeats, except in LRR $_{1}$ of all LGRs except LgrC, and in $\mathrm{LRR}_{6}$ and $\mathrm{LRR}_{16}$ of LgrA, and are often present at the $25^{\text {th }}$ or $26^{\text {th }}$ position (Figures 3 and 4 ). Interestingly, these glycyl residues are located at the boundaries of the consensual alpha-helix, thus not alterating the predominant secondary structure of the 28-residue unit, showing that structural constrains are imposed on the secondary structure of the LRRs. Moreover, only two prolyl residues are present in the 72 LRRs of the LGRs and of pc1145: one is the last residue of $\mathrm{LRR}_{5}{ }^{\mathrm{LgrC}}$ and the other is the $15^{\text {th }}$ residue of $\mathrm{LRR}_{5}{ }^{\mathrm{LgrF}}$ (Figure 4 ). The two prolines are located at positions of low $\alpha$-helix signal. A definition of the protochlamydial 28-meric LRRs could thus be given: the secondary structure of these leucinerich repeat motifs consists mainly of an $\alpha$-helix located at the middle of each unit, and in some repeats, amino acids present at the distal part of the repeat were also predicted to be involved in a small $\beta$-sheet containing $\mathrm{Leu}_{19}, \mathrm{Leu}_{22}$, and Leu $_{24}$. 


\begin{tabular}{|c|c|c|}
\hline & & pc1145 \\
\hline 1001 & 01 & IRDKRAEAIAYYLISNATIESLYLNRNH \\
\hline & 02 & I SDKGMEAFAQALASNTVLETL $Y \mathbf{L} I N N Q$ \\
\hline & & I GERGKKALYGLGLRYGCKIRR \\
\hline & & LgrA \\
\hline & & RFASTYL $Q F A K \mathbf{L} E E \mathbf{L} Q \mathbf{I} R R C K A \mathbf{L} \vee S \mathbf{I} Q \mathbf{L}$ \\
\hline & & DAP LLH T LKADKNP HLKMLFFKT TAPYV \\
\hline & & KGSF TRCPALDLKKAKEEGVRRVLKEIK \\
\hline & & NLEIDSGILL $Q \mathbf{L} Y M N D P K F A S V N L S N Q K$ \\
\hline 35201 & & ISDRGAEVLAHSLASNT TLKSLDLDRNQ \\
\hline & 02 & 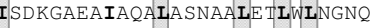 \\
\hline & 03 & I. SDKGAEA IAQSLASNAALWKL S LNGNQ \\
\hline & 04 & ISDQGMEAFAQALASNT ILMDLS LNGNQ \\
\hline & 05 & I.SDQGMKAFAQALASNTSIRVLSINENQ \\
\hline & 06 & I SDKEMEAFAQALASNTSIGVLSLNGNQ \\
\hline & 07 & I SDKGMEAFAQA LASNT TLRTLRLDNNQ \\
\hline & 08 & I SDKGMEAFAQALASNTSI GVL $S \mathbf{L} N G N Q$ \\
\hline & 09 & ISDKGIVALAQALASNT IL SEL SLNENQ \\
\hline & 10 & ISDQGMEAFAQAIASNTALRALRIDNNQ \\
\hline & 11 & 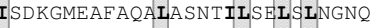 \\
\hline & 12 & I SDQGMEAFAQAIASNI L LALRIDNNQ \\
\hline & 131 & I SDQGMEAFAQTLASNT TLRALRLDNNQ \\
\hline & 14 & ISDKGMEAFAQTMASNTSIRVLSINGNQ \\
\hline & 15 & ISDQGMKAFAQTLVSNT ILMDL SLNGNQ \\
\hline & 16 & ISDKRMKAFAQTLASNTAVGWER RNGQV \\
\hline & & IINKRL \\
\hline & & -grB \\
\hline & & PLAP TYL $Q F A K \mathbf{L} E E \mathbf{L} Q \mathbf{L} K R C V A \mathbf{L} A S \mathbf{I} Q \mathbf{L}$ \\
\hline & & DAP LL L I ILKADKNP HLKT LFF TTF APYF \\
\hline & & KGSF IRCP T LDLETVKKERISKILREIK \\
\hline & & TSEIDR IELFQLYRND SWLNSLSF SYRI \\
\hline 135401 & 011 & ISDKKAEVIANGLAFNTALSELRLNSNQ \\
\hline & 02 & ITDRGVEALAHALAYNTAIKOFWLDRNQ \\
\hline & 03 & ISDEGAKAISKALT SNNTFETISLEYNQ \\
\hline & 04 & ISDEGAEA IAQA IASNT I LRELEINGNQ \\
\hline & 05 & ISDKGAKAIF KAIAYNTVLKKL I I SYNQ \\
\hline & 061 & ISDEGAKAIAQA IASNNTLETLSIEYNQ \\
\hline & 07 & ISDEGMEALAQALASNTALREISINGNQ \\
\hline & 081 & ISDEGMEALAQALASNT TLRELSLINGNQ \\
\hline & & ISDRGMEALARTLASHKYF RVKGNLIKH \\
\hline
\end{tabular}

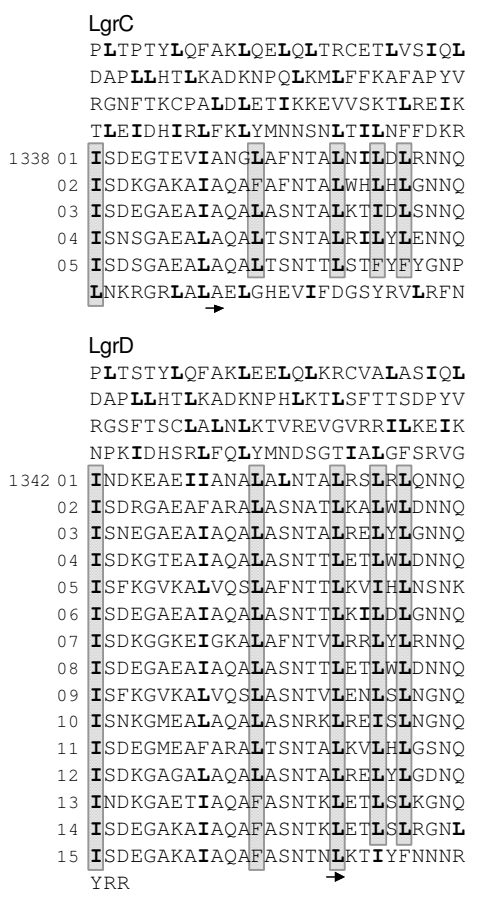

PLTPTYLQF AKL $Q E L Q L T R C E T L V S I Q L$ DAPLLHTLKADKNP OLKMLFFKAFAPYV RGNFTKCPALDLETIKKEVVSKTLREIK ISDEGTEVIANGLAFNTAINIIDIRNNQ

2 I SDKGAKAIAQAEAFNTALWHL H GNNQ I SDEGAEAIAOALASNTALKTIDLSNNO I SNSGAEALAQA LT SNTALRIL YLENNQ ISD SGAEALAQALTSNTTLSTEYEYGNP LgrD RGSFTSCLAINLKTVREVGVRRILKEIK NP K ID HSRLF $Q \mathbf{L} Y M N D$ S GT I ALGE SRVG ISDRGAEAFARALASNATLKAIIDNNO I SNEGAEAIAOALASNTALREL YL GNNO ISDKGTEAIAQALASNTTLETLWLDNNQ ISEKGVKALVQSLAFNT TLKVIHLNSNK WEAIAQALASNTTLKILDLGNNQ ISDKGGKEIGKALAFNTVLRRL LRNNQ ISDEGAEAIAQALASNT TLETLWLDNNQ ISFKGVKALVQSLASNTVLENLSINGNQ SNKGMEALAQALASNRKLREISINGNQ GMEAFARALTSNTALKVL L L SNO INDKGAETIAQAFASNTKLETL SLKGNQ ISDEGAKA

\section{Figure 3}

The 72 Leucine-Rich Repeats (LRRs) of pcl I45 and of the six LGR proteins of $P$. amoebophila. The 28-residue motifs are aligned. The end of the protein is displayed for each LGR protein, starting from the four non-LRR 28-meres preceding the LRR domain. Leucine $(\mathrm{L})$ and the related-isoleucine $(\mathrm{I})$ are indicated in bold. While the common start of the LRR domain as defined by the CAS (Additional File 6) is indicated by the position of the first residue belonging to the LRR domain, the last residue is labeled by an arrow. Only LRR, LgrE is larger (30 residues) than the 7I other 28-meric LRRs: also found in the first LRR of LgrA, $\mathrm{LgrB}$, LgrC and LgrF, a dipeptide EV, underlined in LgrE, is duplicated in LRR, LgrE. All further analyses of the LGRs on the LRRs defined by the CAS are almost exclusively based on homologous 28-meric units and on repeats presenting similarities along at least two thirds in length of the 28-mere.

\section{Evolutionary history of the LRR}

To determine how the LRRs were propagated within the LGR proteins, we inferred phylogenetic trees on nucleotide sequences of the 70 repeats of all LGRs and of the 2 repeats of pc1145 using the Neighbor-Joining method, the Kimura corrected p-distance (Figure 5) and a Bayesian method (Additional File 8(A)). We also drew phylogenic trees with an identity distance calculated from the proportion of conserved amino acids in pairs of repeats (see Additional File 8(B)). This comparison was also represented by a principal coordinate analysis (Figure 6).

These analyses showed that the first repeats of all LGRs except LgrA cluster together. On the Neighbor-joining
(Figure 5), Bayesian (Additional File 8(A)) and UPGMA (Additional File $8(\mathrm{~B})$ ) phylogenetic trees, only three last LRRs of LGRs for which the CAS determined an almost entire last unit (LgrA, LgrE and LgrF) clustered together. This suggests that (i) the LRRs were probably multimerized after serial duplications of the LGR protein genes, (ii) that the repeats propagated independently in the six $\lg r$ genes by rearrangement/recombination of a few ancestral LRRs repeats within the LRR domains defined by the LRR units present at both ends, and (iii) all LGRs probably originated from an ancestral protein exhibiting a few ancestral LRR units able to produce a functional LRR domain. 


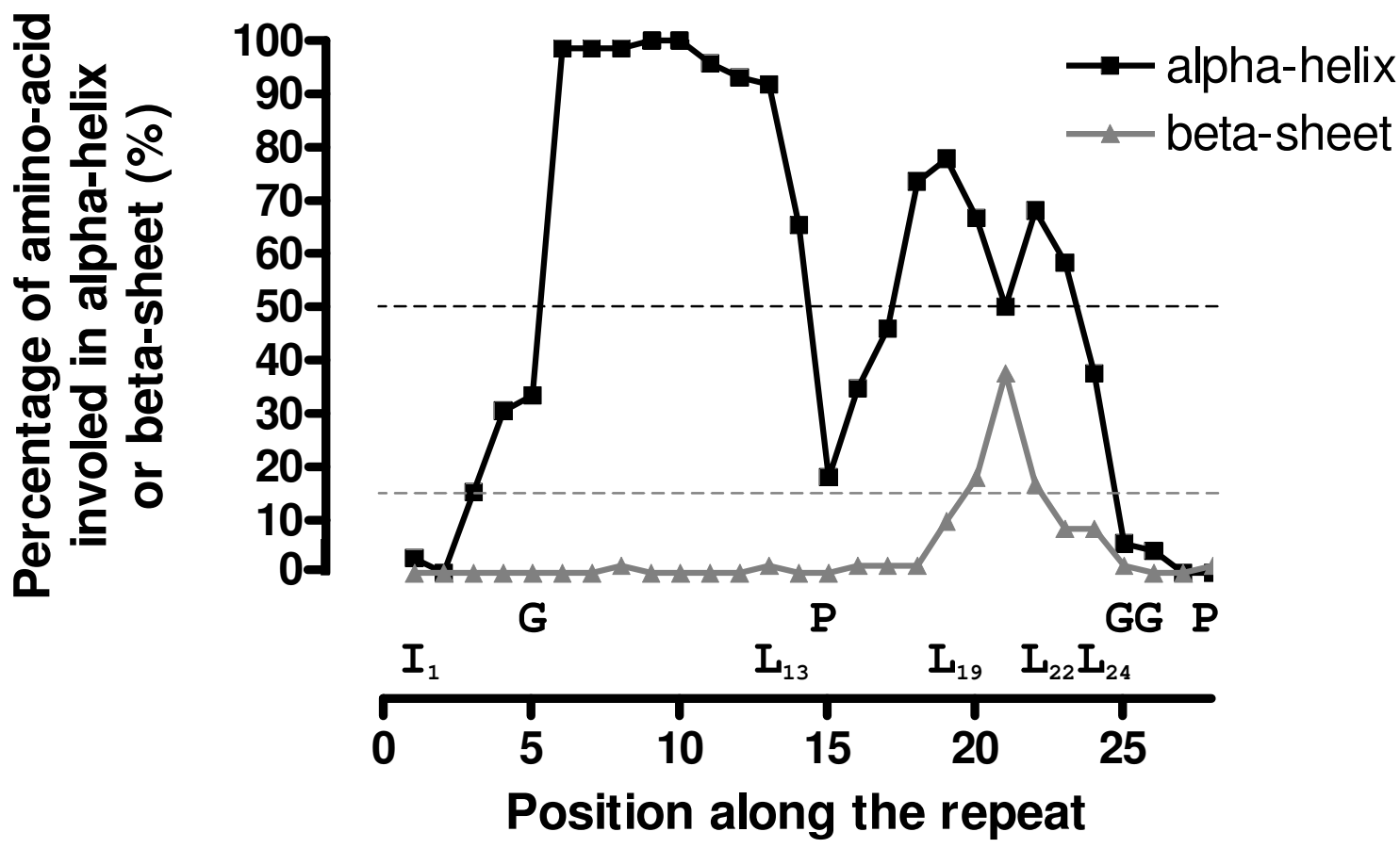

Figure 4

Common secondary structure of the LRRs of $P$. amoebophila defined by the CAS approach. On each position of the consensus of the 28-residue LRRs the proportion of amino acids of the 70 LRRs of the six LGR proteins predicted by NNPREDICT to belong to either an $\alpha$-helix or a $\beta$-sheet is plotted. Perturbating amino acids present in some LRR, i.e. Glycyl (G) and Prolyl (P) residues are posted as they are located on the LRR unit. This figure clearly shows that while secondary structures are present within the LRR units, no particular structural configuration could be observed at the boundaries of the units.

The distance between all six barycenters (centers of gravity) on the two first dimensions of the PCO analysis was represented by an UPGMA tree (Figure 2C). Based on the LRRs domain, this tree was congruent with those inferred with the non-LRR part of LGR proteins (Figures 2A and 2B) and also confirmed that LgrA and LgrE duplicated recently.

Close inspection of the sequence of the LRRs of LgrE (Figure 3) showed that the variations between the repeats are locally distributed, suggesting that the multimerization of the LRRs occurred by serial adjacent duplications (Figure 7A). In order to determine if the repeats result from serial adjacent duplications, the identity scores between peptide sequences were calculated between each LRR of LgrE and i) its two closest repeats or ii) all other repeats of the protein. For all 18 repeats except $\mathrm{LRR}_{2}{ }^{\mathrm{LgrE}}$ and $\mathrm{LRR}_{8}{ }^{\mathrm{LgrE}}$, the average of the identity scores calculated on close neighbors is higher than the counterpart estimated between each of the 18 LRRs and all 17 others, showing that most LRRs are significantly more similar to their two closest LRRs than to all other repeats of the protein taken together (see panel A of Additional File 9(A)). This kind of analysis performed on the nucleotide sequences showed results very similar to those conducted on the amino acid sequences (panel B of Additional File 9(B)).

This identity analysis of the immediate LRR neighborhood was also performed by comparing the 28-meric units separated by 0 to 7 intercalary LRRs (Additional File 9(C)C). We observe on Additional File 9(C)C that immediate neighbors are the most similar. The observation performed with no intercalary sequence corresponds to those posted on additional Files 9AA and 9BB. This graph also 


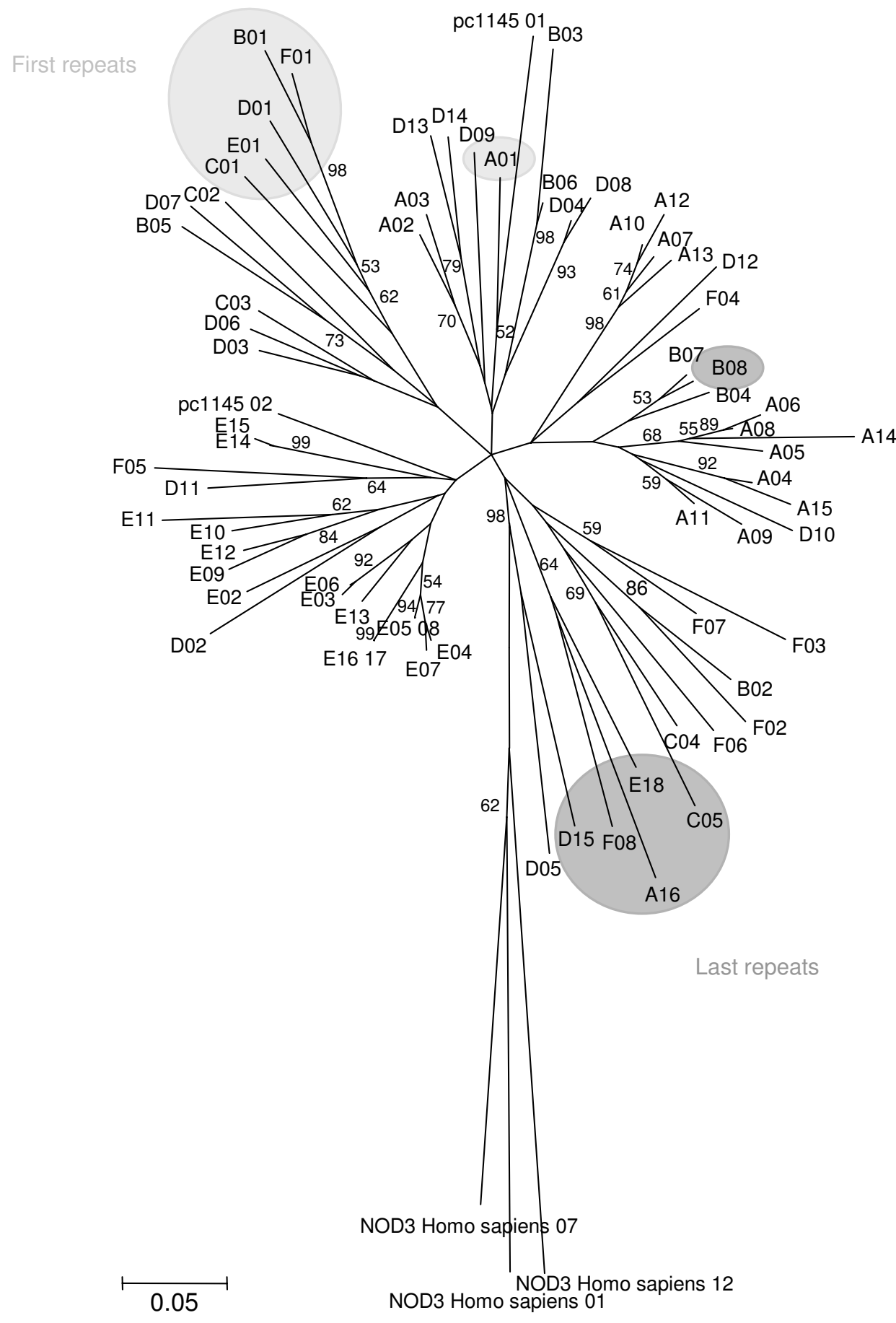

Figure 5

Neighbor-Joining tree inferred from the nucleotide sequence of the 72 LRRs related to LGRs of P. amoebophila and of three repeats of the human NOD3 protein. The p-distance model and the complete deletion parameter were performed with a 500replicate bootstrap analysis. Only bootstrap values higher than $50 \%$ are shown. 


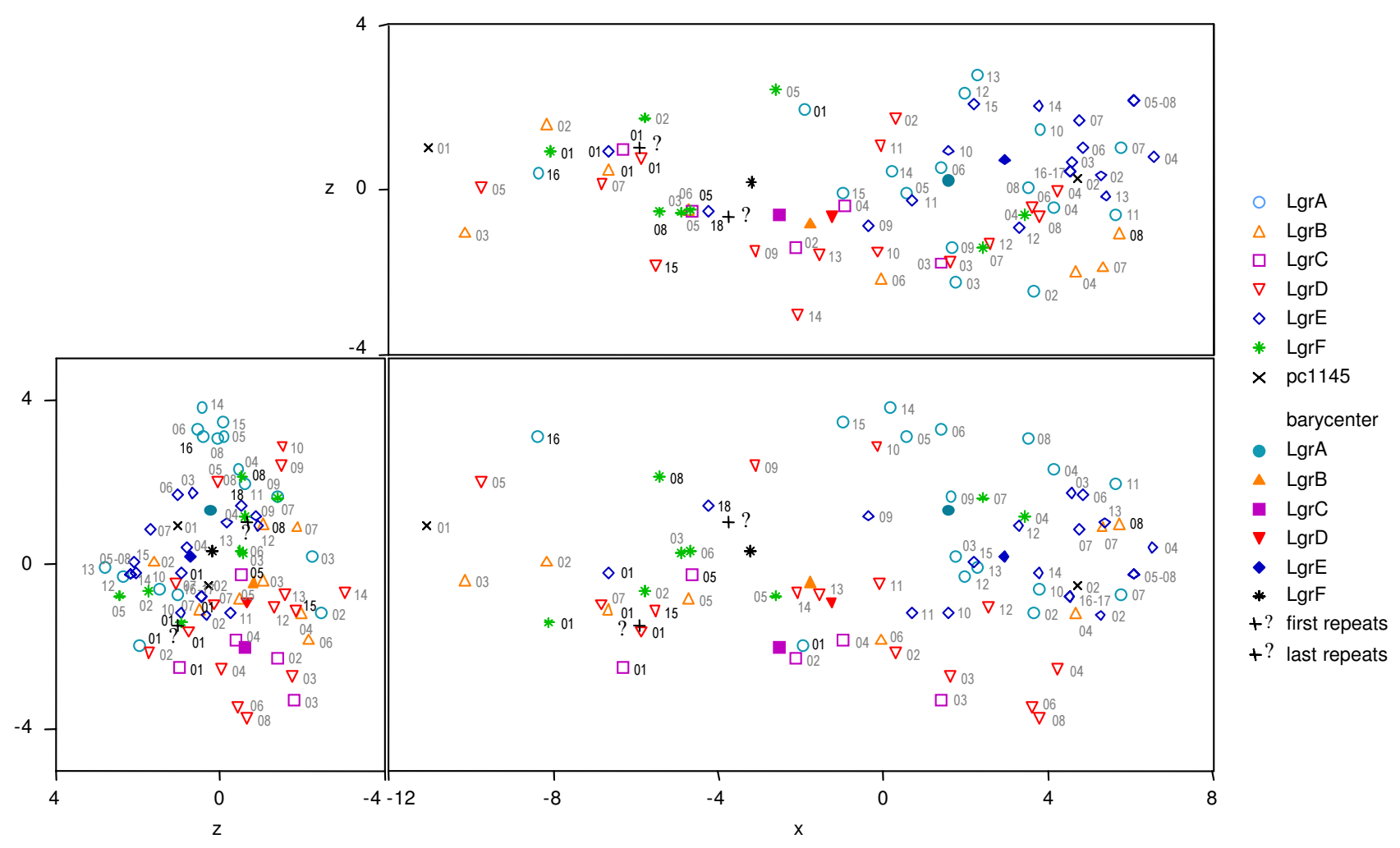

Figure 6

Three main dimensions of a principal coordinate analysis of the 72 LRRs related to LGRs of $P$. amoebophila. The distance is based on the identity of the amino acids of the repeats (Manhattan distance matrix). Filled symbols correspond to the center of mass of the repeats of the protein with the similar empty symbols. The barycenters of the six first repeats $(\alpha)$ and the six last repeats $(\omega)$ are indicated by + and the corresponding abbreviation. The first and the last repeats of the LGRs labelled in black tend to cluster together.

shows that after immediate neighbors, the more similar are those separated by two units. In summary, the latter results suggest that LRR duplication occurred in the LRR domain of LgrE by inserting identical LRR units composed of one or three LRRs.

The average difference for the 18 LRRs of LgrE between the scores calculated on the immediate neighboring repeats and that estimated with all other repeats (1.6) was also calculated for the LRRs of the five other proteins, i.e. LgrA, LgrB, LgrC, LgrD and LgrF. It appeared that these values, although clearly lower, were all positive except for LgrF: $0.50,0.14,0.30,0.10$ and -0.21 respectively, thus confirming that for most LGRs the immediate neighbors of all LRRs are more similar than the others of the same LGR taken together.

\section{Evolution of LRRs by adjacent multimerization}

As the LRRs of the LGRs are concatenates with no intervening sequences, we observed in LgrE that the LRR multimerization probably mainly results from adjacent duplications of DNA stretches of a multiple of 84 nucleotides encoding unique or multiple 28-residue LRRs sequences. These LRR multiplications produced by rearrangements/recombination are favored by the repetition of homologous sequences. Deletion could also appeared during rearrangement. Since a recA gene is present on the genome of Protochlamydia amoebophila UWE25 (pc1995), the RecA protein, which role in homologous recombination is abundantly documented [27,28], might be involved in these internal gene rearrangements. In first analysis, these recombination are independent of a particular 28-residue frame. This hypothesis was suggested by 


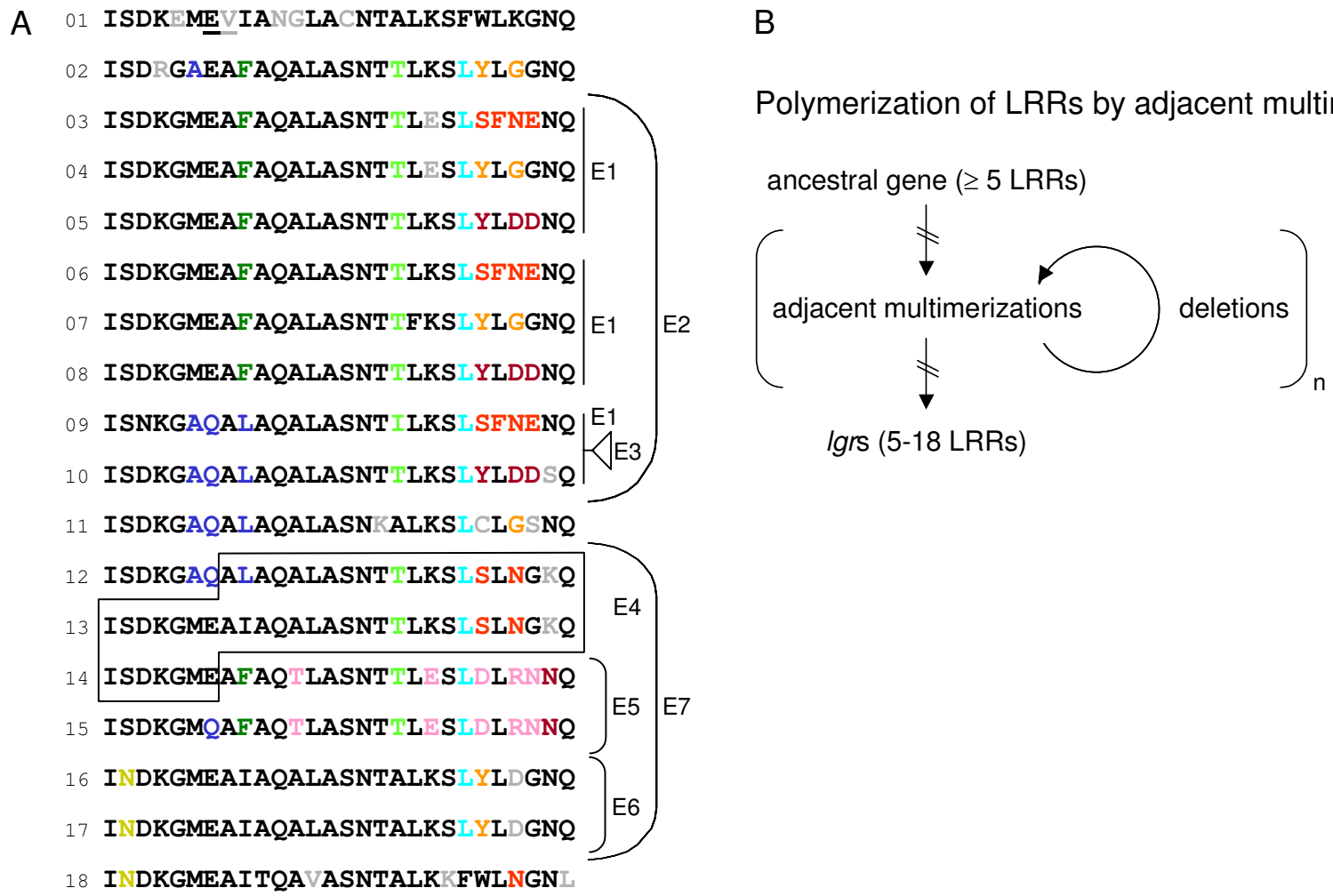

Figure 7

A: Sequence of the LRR domain of LgrE. The different motifs conserved in LRRs are highlighted in colour. Probable events of multimerization and deletion of repeats are indicated by EI to E7 whose numbering is not chronological. A parcimonous scenario is proposed for the multimerization of the LRRs of LgrE. In the first part of the LRR domain: formation of a unit of three different LRRs (EI) that was later triplicated (E2) by two independent duplications in tandem. Finally, a deletion occurred (E3). On the second part of the LRR domain, a triplicate was build (E7), each member of it were duplicated (E4, E5 and E6). Our model shows that multimerization by adjacent concatenation occurred in LgrE. It also shows that LRR, IgrE, LRR IIgrE, and $\mathrm{LRR}_{18} \operatorname{lgrE}$ were not involved directly during this process, suggesting more constrains on their sequences. Furthermore, it points out that the common frame is respected during all duplication events (EI, E2, E3, E5, E6, and E7) except one (E4). Finally, the later event (E4) associated to the deletion (E3) were certainly imposed by structural constrains acting on LRR II lgrE. B: General scheme of the mechanism of the multimerization of the LRRs of the LGRs.

the initial alignments (see Additional File 2) showing that the LRRs of the six LGRs share no obvious common 28residues frame. However, our non a priori approach CAS highlighting a common LRR frame clearly reveal that this common frame was generally respected by the recombination process during the $\mathrm{lr}$ duplication.

These phylogenies and the detailed analysis of the sequence of the LRRs of LgrE enabled us to propose a parsimonious evolutionary scenario for a multimerization mechanism of these LRR domains. The LRRs of P. amoebophila seem to have originated from adjacent duplica- tions and deletions of DNA stretches of a multiple of 84 nucleotides (Figure 7B).

\section{Evolutionary history of LGR neigbourhood of $P$. amoebophila}

The six LGR proteins are very similar, particularly in the non-LRR domain and seem to result from relatively recent duplications in the history of these genes in the parachlamydial genome. To further investigate the evolutionary history of the six lgrs, BLAST searches of sequence homologous to the genes and intergenic sequences that flanked the lgrs were performed against the genome of 
P. amoebophila. Results are shown in Additional File 10. The narrow boxes of various sizes and colors represent the homologous regions present in the close environment of the six lgr genes. Interestingly, a homologous sequence of $633 \mathrm{bp}$ is present on both sides of $\operatorname{lgrA}$ as an inverted repeat. This sequence belongs to a region that is also present downstream from $\operatorname{lgr} C, \operatorname{lgr} E$ and $\lg r F$. Another 360 bp inverted homologous sequence flanks $\lg \mathrm{r} B$ on both side. Moreover, a shorter homologous region is present immediately upstream of the six $\lg r$ genes, that likely corresponds to promoter motifs.

\section{Prediction of promoter and terminator motifs}

To find the promoter motifs of the six LGR proteins, we screened the $500 \mathrm{bp}$ upstream of the translation start site for the presence of the so-called - 35 and - 10 conserved elements of the Escherichia coli canonical s70 promoter, which is also used by Chlamydia spp. [29,30]: the motifs TTG and TANNNT (the underlined nucleotides in the Table S2 are located at the position -35 and -12 of the translation start site), respectively, separated in P. amoebophila by 19 to $21 \mathrm{bp}$. We found 16 putative promoter motifs. Among them, five are very similar (all lgrs except $\operatorname{lgr} C$ ) and are separated by 35-38 bp to the start codon of the five LGR encoding genes (see Additional File 11). A similar sequence is present before $\operatorname{lgr} C$ but its - 35 motif differs from a single nucleotide (TTA instead of the consensual TTG). Calculated on the 50 last bp preceding the putative transcription start site, the $\mathrm{G}+\mathrm{C}$ content of these six sequences ranges from 16.0 to $24.0 \%$, confirming a putative regulatory nature. Moreover, the dinucleotide TG characteristic of promoter sequences [31] is starting at the -15 position. Other similar sequences of $\lg r B, \lg r C, \lg r E$ and $\lg F$ are located at a distance of 152 to $157 \mathrm{bp}$ of the start codon. Their $\mathrm{G}+\mathrm{C}$ content on their last $50 \mathrm{bp}$ range from 32.0 to $42.0 \%$. The remaining seven sequences are not located at similar places before the different LGR encoding genes. The presence of two putative promoter motifs can reveal a complex regulation present in $P$. amoebophila to differentially regulate the expression of the $\lg r$ genes during different developmental stages. The presence of these promoter motifs strongly indicate that all lgrs are expressed genes. In addition, a putative terminator sequence was found in the $500 \mathrm{bp}$ downstream of $\lg \mathrm{g} B$, using the FindTerm software.

\section{Proteins homologous to LGRs in other organisms}

Using BLASTP and PSI-BLAST, proteins homologous to the LGR proteins of $P$. amoebophila were systematically searched in the non-redundant database (nr) maintained on the NCBI website [32]. A large number of proteins present in the genome of different organisms are significantly similar to the C-terminal part of the LGRs proteins corresponding to the last 150 to 505 amino-acids. This region of the LGRs exhibits 28-residue motifs very similar
$(178 / 418=41 \%)$ to the LRRs of the ribonuclease inhibitor (RI)-like subfamily, e.g. mammalian NOD3. The LRRs domain of LGRs also presents significant sequence similarity with DeliriumA (DlrA) of Oryza sativa and of Dictyostelium discoideum involved in the apoptosis [33,34] and with the LRRs of related genes of Ralstonia solanacearum and Legionella pneumophila (Additional File 12). BLASTN searches in the non-redundant database did not reveal any sequence homologous to LGRs.

Since a large number of proteins presented similarity in the LRR regions, we then performed additional BLASTN and BLASTP searches using the remaining parts of each LGR proteins. No proteins of other organisms is homologous to the non-LRR region of the LGRs excepted nine proteins of $D$. discoideum (E-value ranging from $2 \cdot 10^{-13}$ to $5 \cdot 10^{-2}$ ). The latter matches found with the $D$. discoideum proteins corresponded to parts not characterized as catalytic sites or effector domains.

No additional hint was observed during other BLAST investigations (BLASTP and BLASTN) performed against all prokaryotic genomes as well as against those of $D$. discoideum and Arabidopsis thaliana. Since the chromosome sequence of Simkania negevensis, another intracellular amoebal chlamydia, is now available for similarity analyses, we were also interested to determine whether similar proteins were encoded in this genome by BLASTN, TBLASTN and TBLASTX analyses performed at the TIGR website [20]. No sequence larger than 300 nucleotides was identified showing significant similarities to LGRs. The smaller fragments that have been identified by BLASTN were similar to polypeptides located either in the LRR domain or in the remaining part of the LGRs.

\section{Relationship between LRRs domains of LGRs and of other organisms}

We also applied the CAS method to delimit the LRR domains of other LRR proteins homologous to LGR identified by BLAST (Additional File 12). The same motif is conserved among all these LRR domains. The LRRs of mammals, plants and D. discoideum is composed of 28 amino acids, the LRR of $R$. solanacearum and L. pneumophila of 24 residues and those of Tetrahymena thermophila of 30-meric units. Determination of consensus LRR sequences for each protein showed that the repeats are well conserved in the LGRs of $P$. amoebophila, while they are more divergent within the LRR proteins of animals and plants (Additional File 12), indicating that the latters have a longer evolutionary history than the LGRs.

Phylogenetic analyses were performed on the LRR domains of the six LGR proteins and some of the LRR domain of the proteins found by BLAST. All proteins showing similarity (E-value $<10^{-50}$ ) with at least one of 
A

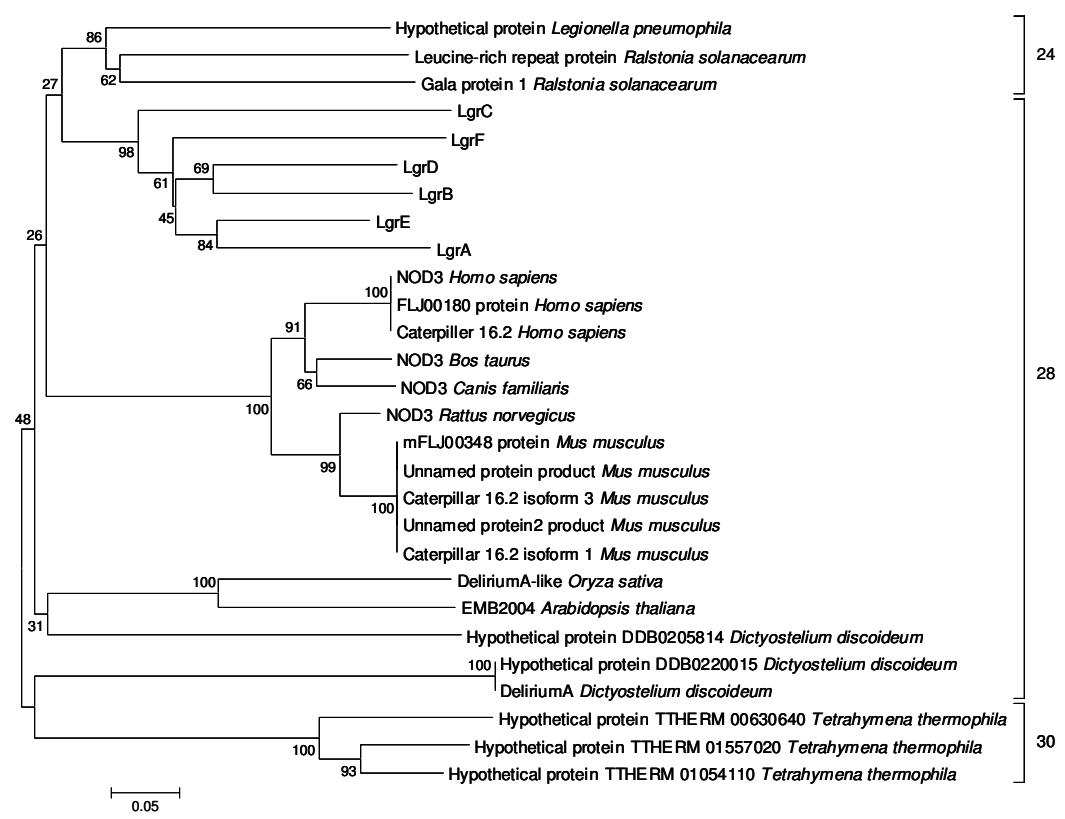

B

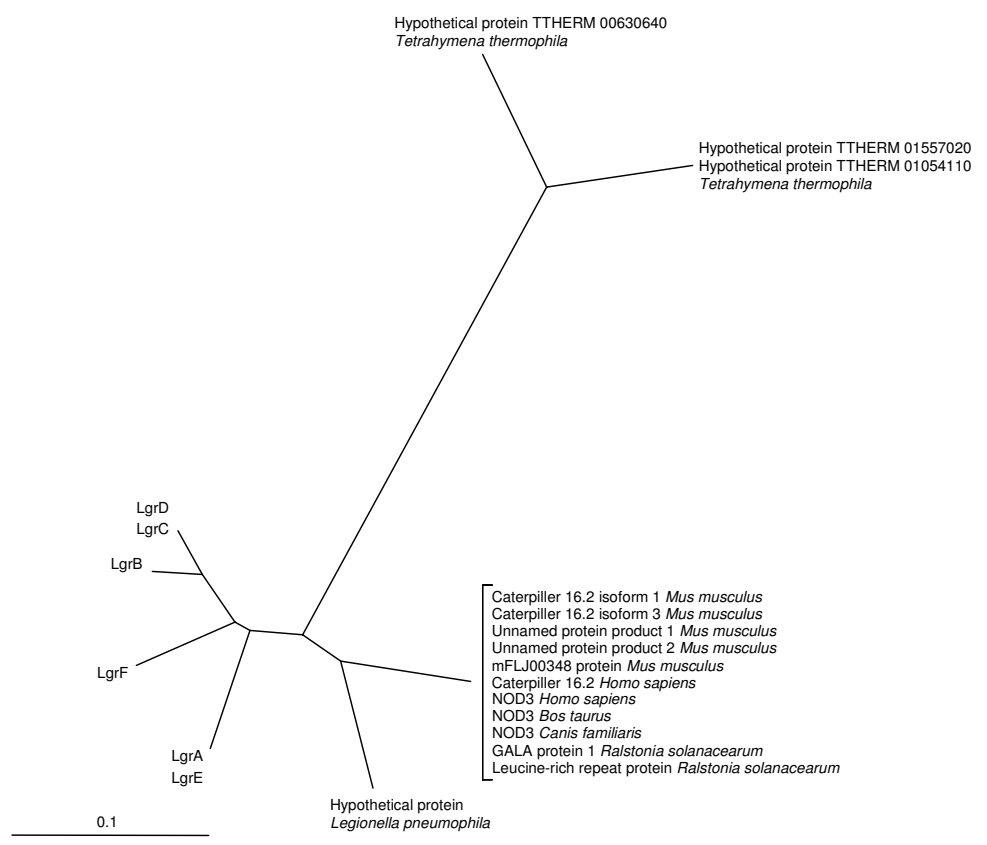

Figure 8

Phylogenetic analyses of the LRR domain of all the proteins presenting a similarity with an expect value $<10-50$ with at least one of the six LGR proteins. A: Neighbor-Joining tree comparing the amino acids sequences by the corrected p-distance.

Bootstraps of 1000 samples are shown in percent. B: UPGMA tree comparing the LRR consensus established on the same set of proteins. This analysis, which measures the identity of the amino acids, was performed only on the LRR consensus established on relatively well conserved repeats: $50 \%$ or more relative positions of the 28 -mere presenting an identical amino acid in $50 \%$ or more of the LRRs of a given protein. Both analyses show that the closest relative of LRRs of LGRs are the bacterial 24meric LRRs of Legionella pneumophila and related bacteria and the 28-meres of eucaryotes. 
the six LGR proteins were included in the analyses (Figure 8A, see Additional File 13). Consequently, the LRRs domains of Toll and Toll-like proteins exhibiting not enough similarity with LGRs were not included in these analyses. Another phylogenetic tree was inferred on the LRR consensus established on each of these proteins presenting a high degree of similarity (Figure 8B). This analysis compared the consensual amino acids at each position and was performed only on the LRR domains that exhibit relatively well conserved repeats (at least 50\% of consensual amino acids).

Both analyses indicated that the closest homologs of the 28-meric units of the LGRs seem to be carried by the 24-meres of the GALA protein 1 (a type III secretion system effector containing a LRR domain and a F-box domain, and considered essential for the virulence of the $R$. solanacearum in some plants [35]), of a LRR-protein of Ralstonia solanacearum, and of a hypothetical protein of Legionella pneumophila.

The next closest homologous LRRs to LRRs of the LGR were NOD proteins of mammals. The NODs of mammals exhibited the best matches in the BLAST searches. Moreover, analysis of the structure of the LRR domain of the LGR proteins showed that they probably belong to the same subfamily, LRR-RI. Like the motifs of LRRs of the LGR proteins, LRR-RI of mammals present 28-amino acid motifs.

\section{Putative roles of LGRs}

We hypothesize that like LRR-RI of mammals, the protochlamydial LRR domain might be involved in bacterial recognition and that each LGR protein might present either slightly different effector domains or be able to recognize different bacterial motifs including nucleic acids. Since by BLAST analyses, we did not find any known effector domain in the non-LRR part of the six LGRs proteins, we searched for a putative effector domain by using the Pfam collection of multiple alignments of sequences determined by hidden Markov models (Additional File 14). All six LGRs exhibited three to four matches with the LRR_1 domain and one match with PetN (a small hydrophobic protein). LgrA, LgrB, LgrE and lgrF exhibited also a match with the lipoprotein_3 domain, present on a Mycoplasma protein and acting as an anchor, suggesting that these LGRs might be associated to membranes, despite the absence of transmembrane domain (see above). Interestingly, LgrA, LgrC, LgrD and lgrE present all a match with the DUF2027 domain, putatively involved in DNA mismatch repair. In addition, each LGRs proteins exhibited a few additional matches (see Additional File 14) that were mainly domains related with DNA metabolism. These putative active domains might thus be involved in the recombination necessary for the concatenation of the
LRRs or might be essential in the recognition of foreign DNA.

It should be pointed out that $\lg r E$ is located near a tra operon likely involved in conjugative DNA transfer [17], which suggests that the LRR-RI motifs of LgrE might be involved in the recognition of a conjugative bacterial partner or in interactions with DNA/RNA molecules since eucaryotic LRR domains were shown to bind double helix of nucleotides [36].

Little is known on the biology of $P$. amoebophila UWE25. However, another related symbiont of amoebae, Parachlamydia acanthamoebae, was shown to resist destruction by macrophages, eliciting no oxidative burst and inducing nearly no secretion of proinflammatory cytokines [13]. Thus, LGR protein might alter the recognition of bacteria by the host cell by saturating recognition sites of the parachlamydial proteins secreted in the amoebal vacuoles containing these bacteria. However, the absence of genetic tools devoted to the study of the obligate intracellular Chlamydiae prevent further genetical investigations of the biological functions of these paralogous proteins. Since Legionella are facultative intracellular bacteria amenable to genetic manipulation and, like the Parachlamydiaceae, able to resist to both free-living amoebae and macrophages, it may be relevant to investigate the role of the Legionella LRR protein to understand the role of LGRs.

\section{Conclusion}

In this work, we describe the evolutionary relationships existing between six large proteins encoded by homologous large $\mathrm{G}+\mathrm{C}$ rich genes $(\lg r A-\lg r F)$ of $P$. amoebophila. By analyzing the LRRs of these six homologous proteins of Protochlamydia amoebophila, we show that these repeats evolved by adjacent multimerization. Our model established on the bacterial 28-meric LRRs of the LGRs can now be challenged in related eucaryotic proteins composed of less conserved LRRs, such as NOD proteins and Toll-like receptors.

\section{Methods \\ Genomic data}

The complete genome sequence and the annotation file of P. amoebophila UWE25 (accession number: NC_005861) are available on the NCBI website [37]. The unfinished genome of strain ATCC VR1471 of Simkania negevensis was available for BLAST analyses at the TIGR website [20].

\section{BLAST analyses}

Similarity analyses using BLASTP (BLOSUM62 matrix), iterative PSI-BLAST and BLASTN searches were performed by selecting default parameters against all available sequences in the non-redundant database available on the NCBI website [32,38]. Other BLASTP searches against all 
the prokaryote genomes, $D$. discoideum and A. thaliana were also conducted on the NCBI website [32] using the BLOSUM62 matrix. Moreover, BLASTN 2.2.13 without filter [38] and MegaBlast of coding and non-coding homologous sequence were performed along the genome of $P$. amoebophila UWE25 [37]. The unfinished genome of S. negevensis was also analyzed by BLASTN, TBLASTN and TBLASTX at the TIGR website [20] using default parameters. For all BLAST analyses, only matches presenting an expect value lower than 0.05 were considered significant.

\section{Pfam analysis}

Unlike BLAST, hidden-Markov-models based proteins profile use a much intense probabilistic approach. Consequently, to search for conserved Pfam domains encoded by the lgrs genes, we performed the analyses using the Pfam 21.0 software against the database available on the Sanger website [39] using defaults parameter.

\section{Cumulative GC skew and intragenic GC skew at the third codon position}

As initially inspired by Grigoriev et al. [40] and then applied by Roten et al. [41], a cumulative GC skew nonponderated to the $\mathrm{G}+\mathrm{C}$ content is a function $\mathrm{Cm}_{\mathrm{GC}}(\mathrm{i})$, measuring at each chromosome position $i$ the excess of Gs by calculating the difference of the number of Gs and Cs, present from the first to the $i$-th nucleotide position:

$$
\mathrm{Cm}_{\mathrm{GC}}(\mathrm{i})=[\mathrm{Gi}]-[\mathrm{Ci}]
$$

where $\mathrm{Cm}$ stands for cumulative. This cumulative GC skew analysis was performed on the complete genome sequence on non-overlapping 1-kb windows.

For each of the 2031 ORFs of $P$. amoebophila, the GC skew at the third codon position of a gene $j \mathrm{Sk}_{\mathrm{GC}_{3}}\left(\mathrm{~g}_{\mathrm{j}}\right)$ was measured by calculating the difference between the frequency of Gs and Cs at the third codon position of the gene j, i.e. $\left[\mathrm{Gg} 3_{\mathrm{j}}\right]$ and $\left[\mathrm{Cg} 3_{\mathrm{j}}\right]$, normalized to the content of both nucleotides [24]:

$$
\mathrm{Sk}_{\mathrm{GC} 3}\left(\mathrm{~g}_{\mathrm{j}}\right)=\left(\left[\mathrm{Gg} 3_{\mathrm{j}}\right]-\left[\mathrm{Cg} 3_{\mathrm{j}}\right]\right) /\left(\left[\mathrm{Gg} 3_{\mathrm{j}}\right]+\left[\mathrm{Cg} 3_{\mathrm{j}}\right]\right)
$$

\section{$G+C$ content and residual cumulative $G+C$ content analyses}

The $\mathrm{G}+\mathrm{C}$ content was calculated with 5 -kb sliding windows moving in 1-kb steps. Derived from the GC profile approach [42], residual cumulative $\mathrm{G}+\mathrm{C}$ content analysis reveals minor local variations of $\mathrm{G}+\mathrm{C}$ content at the nucleotide level without being affected by windows of arbitrary size [17]. First, a cumulative $\mathrm{G}+\mathrm{C}$ content curve is drawn by plotting at each chromosome position $i$ the number of Cs and Gs from the first to the $i$-th position. Next, a linear regression is calculated, and finally a bidimensional graph is drawn on which chromosome positions on the hori- zontal axis are plotted versus the residues, i.e. the distances from each data to the linear regression, on the vertical axis. As already pointed out [17], while a flat segment on this curve reveals a DNA stretch locally exhibiting a $\mathrm{G}+\mathrm{C}$ content similar to the chromosome counterpart, a segment presenting a positive or a negative slope indicates a region enriched or depleted in Cs and Gs, respectively.

\section{Alignment and phylogenetic analyses}

The alignment of the six proteins encoded by Large G+CRich genes $(\lg r)$ was performed with ClustalW [43] in MEGA 3.1 [44] using default parameters. Neighbor-Joining, Minimum Evolution and Maximum Parsimony phylogenetic analyses were performed on amino-acid and nucleotide sequences of various datasets (six LGR proteins with or without related proteins identified by BLAST; either whole proteins or their LRR or non-LRR domains) with the same software using $\mathrm{p}$-distance and the complete deletion option.

On the same datasets, we performed Bayesian analyses using MrBayes version 3.0b4, a program inferring Bayesian phylogenies $[45,46]$. The posterior probability validating the final tree is estimated using a Monte Carlo Markov Chain algorithm establishing a chain of possible dendrograms, which randomly wanders the tree space by sampling dendrograms until an equilibrium distribution is reached.

\section{Secondary structure prediction and transmembrane helices prediction}

Prediction of the secondary structure of the LRRs were performed using two different softwares on the whole LGR sequences: i) NNPREDICT with the tertiary structure class option not selected $[47,48]$, and ii) PREDATOR able to PREDict protein secondary structure- from a single sequence or a set of sequences $[49,50]$.

Furthermore, the presence of putative transmembrane protein segments in the six LGRs were challenged by the TMHMM Server v. 2.0 designed for the prediction of TransMembrane helices based on a Hidden Markov Model [51,52]).

\section{Promoter and terminator detection}

The 500 bp upstream of the six lgrs were screened for the presence of the Escherichia coli canonical $\sigma^{70}$ promoter. We searched the more conserved positions of the so-called 35 and -10 elements, i.e. the motifs TTG and TANNNT, separated by 19 to 21 bp [29,30], $\mathrm{N}$ representing a nondefined nucleotide.

The $500 \mathrm{bp}$ downstream of the six lgrs were screened for the presence of terminator motifs with the software FindTerm designed for bacterial sequences [53]. 


\section{Determination of the common LRR frame by Cumulative Alignment Score (CAS)}

For each LGR, we first defined by BLAST an initial 28-residue LRR consensus sequence by assigning at each of its 28 relative positions the amino acid present in at least half of all LRRs. Then, respecting the 28-residue frame used to determine the initial consensus, each amino acid of the LGRs is compared by an identity analysis to the consensus defined for each LGR: an alignment score is calculated by assigning 0 or 1 to each amino acid, respectively, different or identical to the amino acid of the consensus sequence. Finally, a Cumulative Alignment Score (CAS) curve is drawn by plotting to each amino acid position of the LGRs the sum of its alignment score to those of all preceding positions. On this representation, all six LGRs displayed a C-terminal steep slope region corresponding to the LRR region. Preliminary analyses showed that the limits of the LRR domains defined by our method are fully independent of the initial consensus frame. The CAS approach was able to unambiguously define a common frame to all LRRs of the six LGRs and thus to accurately define the LRR region of these proteins and of other proteins such as the mammalian NODs.

\section{Amino acid identity analyses on LRR sequences and related consensus}

In addition to standard phylogenetic methods, we also compared the amino acid identity between pairs of any combination of the 72 LRRs of the six LGRs ( 70 units) and a small additional LRR protein (2 units). The divergence $\mathrm{d}_{\mathrm{ab}}$ between the LRRs $\mathrm{a}$ and $\mathrm{b}$ is calculated from the frequency of common amino acids $\mathrm{c}_{\mathrm{ab}}$ shared by both repeats at the same relative position of the polypeptide:

$$
\mathrm{d}_{\mathrm{ab}}=1-\mathrm{c}_{\mathrm{ab}}
$$

Such distances calculated for all pair combinations of the 72 LRRs are compared either by an UPGMA (Unweighted Pair Group Method with Arithmetic mean) dendrogram (Phylip 3.65; [54]) or bidimensionally using a principal coordinate analysis (see below).

This evolutionary distance based on identity was also used to compare within the LGRs the identity existing between a given LRR and two neighboring units concatenated to the LRR or separated by a same number of intercalary LRRs.

This approach was also used to compare the LRR consensus sequences specific to each protein. These comparisons were performed only on consensus sequences exhibiting a consensual amino acid in at least half of the 28 relative positions. The identity between a pair of given consensus LRR was defined as the number of consensual amino acids common to this pair divided by the number of consensual positions shared by both consensus sequences. The divergence between two LRR consensus sequences is calculated as above (equation 3). We then used these identity rates as evolutionary distances to infer a UPGMA tree.

\section{Multivariate comparisons: principal coordinate (PCO) and principal component analyses (PCA)}

All PCO and PCA analyses were carried out with the software MVSP 3.1 [55]. Practically, both PCO and PCA represent the variability existing between $\mathrm{n}$ data in a n-dimension space. For each dimension, an eigenvalue is calculated. The bi/tridimensional graph able to best discriminate the data represents the $\mathrm{n}$ elements in the two/three dimensions exhibiting the highest eigenvalues [56]. PCA were chosen for codon usage analyses of all ORFs of $P$. amoebophila and PCO displaying a slightly more biased representation was selected for comparison of LRR since it was possible to replace Euclidean distances by Manhattan counterparts, the latter comparison exhibiting a slightly better data resolution.

\section{Authors' contributions}

ME performed all the analyses of this work presented at University of Lausanne as her Master Thesis directed by GG (standard phylogeny, sequence alignment, protein secondary structure, biology of Chlamydia-like organisms) and co-supervised by CAHR (in silico comparative genomics, non-a priori approaches, LRR comparison tools, multivariate analyses, Bayesian phylogeny). ME drafted the manuscript that was improved and approved by all authors.

\section{Additional material}

\section{Additional File 1}

Principal component analysis (PCA) of the codon usage of the 2031 ORFs of $\mathbf{P}$. amoebophila. This analysis shows that lgrs present a codon usage similar to most other $\mathrm{P}$. amoebophila ORFs.

Click here for file

[http://www.biomedcentral.com/content/supplementary/14712148-7-231-S1.pdf]

\section{Additional File 2}

Alignment of the six LGR proteins of $\mathrm{P}$. amoebophila. This alignment reveals how these proteins are closely related and detects a 28-residue period at the carboxy-terminal end of the sequences.

Click here for file

[http://www.biomedcentral.com/content/supplementary/14712148-7-231-S2.ppt]

\section{Additional File 3}

Predicted secondary structure of the six LGRs. This figure shows the secondary structure of the six LGR proteins of $\mathrm{P}$. amoebophila, which is highly similar between LgrA and LgrE.

Click here for file

[http://www.biomedcentral.com/content/supplementary/14712148-7-231-S3.ppt] 


\section{Additional File 4}

Secondary structure of LGR proteins. The data shown in this table are the percentage of the amino acids predicted to be involved in $\alpha$-helixes and $\beta$-sheets.

Click here for file

[http://www.biomedcentral.com/content/supplementary/1471-

2148-7-231-S4.doc]

\section{Additional File 5}

Leucine content of the six LGR proteins. These analyses reveals no particular leucine enrichment of the LRR domain.

Click here for file

[http://www.biomedcentral.com/content/supplementary/14712148-7-231-S5.ppt]

\section{Additional File 6}

Cumulative alignment score of the six LGR proteins. Representation of the cumulative alignment score of LgrA to LgrF.

Click here for file

[http://www.biomedcentral.com/content/supplementary/1471-

2148-7-231-S6.ppt]

\section{Additional File 7}

Secondary structure of LRRs of the LGR proteins and related proteins. This figure shows the secondary structure of the LRRs of LgrA to LgrF of P. amoebophila, of the human NOD3 protein and of a LRR-protein of Legionella pneumophila.

Click here for file

[http://www.biomedcentral.com/content/supplementary/1471-

2148-7-231-S7.ppt]

\section{Additional File 8}

Phylogeny of the 72 LRRs related to LGRs. Phylogenetic analyses revealing that first and last repeats LRRs of LGRs proteins tend to cluster together.

Click here for file

[http://www.biomedcentral.com/content/supplementary/14712148-7-231-S8.ppt]

\section{Additional File 9}

Identity scores between adjacent LRRs of the LGRs. These figures reveal that adjacent LRRs are closely related.

Click here for file

[http://www.biomedcentral.com/content/supplementary/1471-

2148-7-231-S9.ppt]

\section{Additional File 10}

Immediate neighborhood of lgrs. This figure shows the local genetic map of the six lgr genes of P. amoebophila.

Click here for file

[http://www.biomedcentral.com/content/supplementary/14712148-7-231-S10.ppt]

\section{Additional File 11}

Putative promoter motifs of the six lgrs. A list of putative promoter motifs present upstream of the six lgr genes of $\mathrm{P}$. amoebophila is provided in this table.

Click here for file

[http://www.biomedcentral.com/content/supplementary/14712148-7-231-S11.doc]

\section{Additional File 12}

LRR consensus of the LGR proteins and of related proteins. Table listing proteins presenting an identity (BLASTP) of less than $10^{-50}$ with at least one of the LGR proteins and showing for each protein its LRR amino acid consensus.

Click here for file

[http://www.biomedcentral.com/content/supplementary/14712148-7-231-S12.doc]

\section{Additional File 13}

Phylogenetic analyses of the LRR domain of LGRs and related proteins. Phylogenetic analyses showing the relatedness of LRRs of LGRs with LRR proteins of proteobacteria and NODs of mammals.

Click here for file

[http://www.biomedcentral.com/content/supplementary/14712148-7-231-S13.ppt]

\section{Additional File 14}

Pfam analyses on all Lgrs. Putative functions of the conserved Pfam domains of LGRs are shown in this table.

Click here for file

[http://www.biomedcentral.com/content/supplementary/14712148-7-231-S14.doc]

\section{Acknowledgements}

We warmly acknowledge David Bouvier, Bernard Barbier, Victor Jongeneel, Vladimir Lazarevic, Christophe Carnoy and Leonard Studer respectively for helping us to use the right number prefixes [57], for enlightening discussions about the secondary structure of LRRs, peptide nomenclature, promoter biology, innate immunity and multivariate analyses. We also thank Philip Tarr and François Collyn for reviewing this manuscript and Geneviève Goy for resequencing the 30-meric repeat of LgrE. Finally, we thank one of the reviewer to propose us to perform Pfam analyses, which revealed in the LgrE associated to the putative conjugative DNA transfer system several Pfam domains specialized in DNA metabolism. Preliminary S. negevensis sequence data was obtained from The Institute for Genomic Research website [20]. Gilbert Greub's research is supported by the Swiss National Science Foundation n ${ }^{\circ}$ FN 3200BO-I 16445. Gilbert Greub is supported by the Leenards Foundation through a career award entitled "Bourse Leenards pour la relève académique en médecine clinique à Lausanne". Claude-Alain Roten was supported by the Foundation for Advancements of Medical Microbiology and Infectious Diseases (FAMMID).

\section{References}

I. Collingro A, Toenshoff ER, Taylor MW, Fritsche TR, Wagner M, Horn M: Candidatus Protochlamydia amoebophila, an endosymbiont of Acanthamoeba spp. Int J Syst Evol Microbiol 2005, 55: $1863-1866$.

2. Fritsche TR, Horn M, Wagner M, Herwig RP, Schleifer KH, Gautom RK: Phylogenetic diversity among geographically dispersed Chlamydiales endosymbionts recovered from clinical and environmental isolates of Acanthamoeba spp. Appl Environ Microbiol 2000, 66:2613-2619.

3. Greub G, Raoult D: Crescent bodies of Parachlamydia acanthamoeba and its life cycle within Acanthamoeba polyphaga: an electron micrograph study. Appl Environ Microbiol 2002, 68:3076-84.

4. Amann R, Springer N, Schonhuber W, Ludwig W, Schmid EN, Muller $K D$, Michel R: Obligate intracellular bacterial parasites of acanthamoebae related to Chlamydia spp. Appl Environ Microbiol 1997, 63:||5-2|. 
5. Horn M, Wagner M, Muller KD, Schmid EN, Fritsche TR, Schleifer $\mathrm{KH}$, Michel R: Neochlamydia hartmannellae gen. nov., sp. nov. (Parachlamydiaceae), an endoparasite of the amoeba Hartmannella vermiformis. Microbiology 2000, | 46: | 23 |-9.

6. Greub G, Raoult D: Parachlamydiaceae: potential emerging pathogens. Emerg Infect Dis 2002, 8:625-30.

7. Corsaro D, Greub G: Pathogenic potential of novel Chlamydiae and diagnostic approaches to infections due to these obligate intracellular bacteria. Clinical Microbiology Reviews 2006 1 9:283-297.

8. Birtles RJ, Rowbotham TJ, Storey C, Marrie TJ, Raoult D: Chlamydialike obligate parasite of free-living amoebae. Lancet 1997. 349:925-6.

9. Marrie TJ, Raoult D, La Scola B, Birtles RJ, de Carolis E: Legionellalike and other amoebal pathogens as agents of communityacquired pneumonia. Emerg Infect Dis 2001, 7:1026-9.

10. Greub G, Berger P, Papazian L, Raoult D: Parachlamydiaceae as rare agents of pneumonia. Emerg Infect Dis 2003, 9:755-6.

II. Greub G, Boyadjiev I, La Scola B, Raoult D, Martin C: Serological hint suggesting that Parachlamydiaceae are agents of pneumonia in polytraumatized intensive care patients. Ann $N Y$ Acad Sci 2003, 990:31 1-9.

12. Greub G, Mege JL, Raoult D: Parachlamydia acanthamoebae enters and multiplies within human macrophages and induces their apoptosis. Infect Immun 2003, 7 I:5979-85.

13. Greub G, Desnues B, Raoult D, Mege JL: Lack of microbicidal response in human macrophages infected with Parachlamydia acanthamoebae. Microbes Infect 2005, 7:714-9.

14. Greub G, Mege JL, Gorvel JP, Raoult D, Meresse S: Intracellular trafficking of Parachlamydia acanthamoebae. Cell Microbiol 2005, 7:58I-9.

I5. Horn M, Collingro A, Schmitz-Esser S, Beier CL, Purkhold U, Fartmann B, Brandt P, Nyakatura GJ, Droege M, Frishman D, Rattei T, Mewes HW, Wagner M: Illuminating the evolutionary history of chlamydiae. Science 2004, 304:728-30.

16. Horn M, Collingro A, Schmitz-Esser S, Wagner M: Environmental Chlamydia genomics. In Chlamydia: genomics and pathogenesis Edited by: Bavoil PM, Wyrick PB. Norfolk: Horizon Bioscience; 2006:25-44.

17. Greub G, Collyn F, Guy L, Roten CA: A genomic island present along the bacterial chromosome of the Parachlamydiaceae UWE25, an obligate amoebal endosymbiont, encodes a potentially functional F-like conjugative DNA transfer system. BMC Microbiol 2004, 4:48.

18. Ogata H, Renesto P, Audic S, Robert C, Blanc G, Fournier PE, Parinello H, Claverie JM, Raoult D: The genome sequence of Rickettsia felis identifies the first putative conjugative plasmid in an obligate intracellular parasite. PLoS Biol 2005, 3:e248.

19. Ogata H, La Scola B, Audic S, Renesto P, Blanc G, Robert C, Fournier PE, Claverie JM, Raoult D: Genome sequence of Rickettsia bellii illuminates the role of amoebae in gene exchanges between intracellular pathogens. PLoS Genet 2006, 2:e76.

20. The Institute for Genomic Research (TIGR) website providing by BLAST access to TIGR's unfinished genomes sequences [http://tigr.org/]

2I. Inohara N, Chamaillard M, McDonald C, Nunez G: NOD-LRR proteins: role in host-microbial interactions and inflammatory disease. Annu Rev Biochem 2005, 74:355-83.

22. Bertin J, DiStefano PS: The PYRIN domain: a novel motif found in apoptosis and inflammation proteins. Cell Death and Differentiation 2000, 7:1273-1274.

23. Kobe $B$, Kajava AV: The leucine-rich repeat as a protein recognition motif. Curr Opin Struct Biol 200 I, I I:725-32.

24. Lobry JR, Sueoka N: Asymmetric directional mutation pressures in bacteria. Genome Biol 2002, 3: I-research0058.

25. The Pfam protein families database: description of Mycoplasma specific lipoproteins [http://pfam.jouy.inra.fr/cgi-bin/getdesc?name=Lipoprotein 3]

26. Casson N, Greub G: Resistance of different Chlamydia-like organisms to quinolones and mutations in the quinolone resistance-determining region of the DNA gyrase $A-$ and topoisomerase-encoding genes. Int J Antimicrob Agents 2006, 27:54I-4.

27. Shibata T, DasGupta C, Cunningham RP, Radding CM: Homologous pairing in genetic recombination: formation of $D$ loops by combined action of RecA protein and a helix-destabilizing protein. Proc Natl Acad Sci USA 1980, 77:2606-I0.

28. Fulconis R, Mine J, Bancaud A, Dutreix M, Viovy JL: Mechanism of RecA-mediated homologous recombination revisited by single molecule nanomanipulation. EMBO J 2006, 25:4293-304.

29. Timms P, Towsey M, Hogan J, Mathews S: Whole genome transcript start site and promoter prediction in Chlamydia. Chlamydial Infections: Proceedings of the Eleven International Symposium on Human Chlamydial Infections 2006:13-16.

30. Hefty PS, Stephens RS: Chlamydial type III secretion system is encoded on ten operons preceded by sigma 70-like promoter elements. J Bacteriol 2007, I 89:198-206.

31. Helmann JD: Compilation and analysis of Bacillus subtilis sigma A-dependent promoter sequences: evidence for extended contact between RNA polymerase and upstream promoter DNA. Nucleic Acids Research 1995, 23:2351-60.

32. Website of the National Center for Biotechnology Information (NCBI) [http://www.ncbi.nlm.nih.gov/]

33. Adam M, Levraud JP, Golstein P: Delirium A, not such a crazy mutant. Proceedings of the International Dictyostelium Conference 2000 [http://dictybase.org/DictyAnnualConference/dicty2000.pdf]. Dundee, Scotland

34. Levraud JP, Adam M, Luciani MF, Dubus-Bonnet V, Roisin-Bouffay C, Golstein P: Genetic and morphological analysis on Dictyostelium cell death. In Proceedings of the International Dictyostelium Conference Edited by: Firtel RA, Loomis WL. California, USA; 200I.

35. Angot A, Peeters N, Lechner E, Vailleau F, Baud C, Gentzbittel L, Sartorel E, Genschik P, Boucher C, Genin S: Ralstonia solanacearum requires F-box-like domain-containing type III effectors to promote disease on several host plants. Proc Natl Acad Sci USA 2006, 103:14620-5.

36. Bell JK, Botos I, Hall PR, Askins J, Shiloach J, Segal DM, Davies DR: The molecular structure of the Toll-like receptor 3 ligandbinding domain. Proc Natl Acad Sci USA 2005, 2: I0976-80.

37. Genome of Candidatus Protochlamydia amoeophila strain UWE25. [http://www.ncbi.nlm.nih.gov/sites/entrez?Db=genome\& Cmd=ShowDetailView\&TermToSearch=399]

38. Altschul SF, Madden TL, Schäffer AA, Zhang J, Zhang Z, Miller W, Lipman DJ: Gapped BLAST and PSI-BLAST: a new generation of protein database search programs. Nucleic Acids Res 1997, 25:3389-3402.

39. Sanger website for Pfam analyses [http://www.sanger.ac.uk/ Software/Pfam/]

40. Grigoriev A: Analyzing genomes with cumulative skew diagrams. Nucleic Acids Res 1998, 26:2286-90.

41. Roten CA, Gamba P, Barblan JL, Karamata D: Comparative Genometrics (CG): a database dedicated to biometric comparisons of whole genomes. Nucleic Acids Res 2002, 30:|42-4.

42. Zhang R, Zhang CT: A systematic method to identify genomic islands and its applications in analyzing the genomes of Corynebacterium glutamicum and Vibrio vulnificus CMCP6 chromosome I. Bioinformatics 2004, 20:6 I 2-22.

43. Thompson JD, Higgins DG, Gibson TJ: CLUSTAL W improving the sensitivity of progressive multiple sequence alignment through sequence weighting, position-specific gap penalties and weight matrix choice. Nucleic Acids Res 1994, 22:4673-80.

44. Kumar S, Tamura K, Nei M: MEGA3: Integrated software for Molecular Evolutionary Genetics Analysis and sequence alignment. Briefings in Bioinformatics 2004, 5: I 50- 163.

45. Ronquist F, Huelsenbeck JP: MrBayes 3: Bayesian phylogenetic inference under mixed models. Bioinformatics 2003, 19: I572-4.

46. Huelsenbeck JP, Ronquist F: MrBayes: Bayesian inference of phylogenetic trees. Bioinformatics 200 I, I 7:754-5.

47. NNPREDICT website: secondary structure analyses of proteins [http://www.cmpharm.ucsf.edu/ nomi/nnpredict.html]

48. Kneller DG, Cohen FE, Langridge R: Improvements in protein secondary structure prediction by an enhanced neural network. J Mol Biol 1990, 2 | 4: |7|-|82.

49. PREDATOR website: secondary structure analyses of proteins [http://bioweb.pasteur.fr/seqanal/interfaces/predator-simple.html]

50. Frishman D, Argos P: Incorporation of long-distance interactions into a secondary structure prediction algorithm. Protein Engineering 1996, 9:133-142.

51. TMHMM Server v. 2.0 designed for the prediction of TransMembrane helices [http://www.cbs.dtu.dk/services/TMHMM-2.0/] 
52. Krogh A, Larsson B, von Heijne G, Sonnhammer EL: Predicting transmembrane protein topology with a hidden Markov model: application to complete genomes. J Mol Biol 200I, 305:567-80.

53. FindTerm Software: detection of gene terminators [http:// sun I.softberry.com/berry.phtml?topic=findterm\&group=programs\& subgroup $=$ gfindb]

54. Felsenstein J: PHYLIP-Phylogeny inference package. Cladistics 1989, 5:164-166.

55. Software MVSP 3.I: multivariate analyses [http://www.kovcomp.com/mvsp/index.html]

56. Gower JC: Some distance properties of latent root and vector methods used in multivariate analysis. Biometrika 1966, 53:325-338.

57. Prefixes used in chemistry [http://home.comcast.net/ igpl/ NWC.html]

Publish with Bio Med Central and every scientist can read your work free of charge

"BioMed Central will be the most significant development for disseminating the results of biomedical research in our lifetime. " Sir Paul Nurse, Cancer Research UK

Your research papers will be:

- available free of charge to the entire biomedical community

- peer reviewed and published immediately upon acceptance

- cited in PubMed and archived on PubMed Central

- yours - you keep the copyright

Submit your manuscript here:

http://www.biomedcentral.com/info/publishing_adv.asp
BioMedcentral

Page 19 of 19

(page number not for citation purposes) 